\title{
₹USGS
}

science for a changing world

\section{Time-domain electromagnetic signatures of polymetallic vein deposits in Cottonwood Canyon area, Santa Cruz County, Arizona}

By Mark W. Bultman ${ }^{1}$

Open-File Report 02-18

Version 1.0

2002

This report is preliminary and has not been reviewed for conformity with U.S. Geological Survey (USGS) editorial standards or with the North American Stratigraphic Code. Any use of trade, firm, or product names is for descriptive purposes only and does not imply endorsement by the U.S. Government.

U.S. Department of the Interior U.S. Geological Survey

${ }^{1}$ Tucson, Arizona 85719 


\section{Contents}

Abstract 6

\section{Part 1. Background}

1.1 Introduction 7

1.2 Geology and mineral resources of the Cottonwood Canyon area

1.3 TEM data 12

1.4 CDT data used in this report 18

\section{Part 2. Geophysical signature of polymetallic vein deposits in the Cottonwood Canyon area}

2.1 Introduction 19

2.2 Magnetic anomaly map in relation to the geology and polymetallic vein deposits of the Cottonwood Canyon area 20

2.3 Airborne TEM data in relation to the geology and polymetallic vein deposits of the Cottonwood Canyon area 23

2.3.a Analysis based on individual CDTs 23

2.3.b General features visible in CDTs in the Cottonwood Canyon area

2.3.c Interpretation of individual CDTs 25

2.4 Three-dimensional interpretation of airborne TEM data in relation to the geology and polymetallic vein deposits of the Cottonwood Canyon area 31

2.5 Summary of the relation of geophysical data to the geology and mineral resources of the Cottonwood Canyon area 


\section{Conclusions $\quad 38$}

\section{References cited 40}

\section{Appendix 1. Data from the Cottonwood Canyon airborne time-domain electromagnetic survey of the Cottonwood Canyon area, southern Arizona 43}

\section{Appendix 2. Comparison of CDT-based depth estimates with gravity- based depth estimates, Cottonwood Canyon area, Arizona 44}

\section{Tables}

Table 1. Pointer references of geologic and mineral-related features to CDTs, Earth's magnetic field data, and a geologic map 29

\section{Figures}

Fig. 1. Sketch map of Arizona showing location of the study area

7

Fig. 2. Photograph of the western margin of the Santa Rita Mountains, including the study area, from Arizona Interstate Highway 19 in the Santa Cruz Valley.

Fig. 3. Receiver "birds" and transmitting coil around perimeter of aircraft.

Fig. 4. GEOTEM system in operation.

14

Fig. 5. Comparison of CDT data with down hole-resistivity logs for nine test wells at Fort Huachuca, Ariz. 16

Fig. 6. Vertical distance from water table of CDT profiles in basin fill of the upper San Pedro basin 17

Fig. 7. CDT 1 with Earth's magnetic field data and geologic map

Fig. 8. CDT 2 with Earth's magnetic field data and geologic map

Fig. 9. CDT 3 with Earth's magnetic field data and geologic map 
Fig. 10. CDT 4 with Earth's magnetic field data and geologic map

Fig. 11. CDT 5 with Earth's magnetic field data and geologic map

Fig. 12. CDT 6 with Earth's magnetic field data and geologic map

Fig. 13. CDT 7 with Earth's magnetic field data and geologic map

Fig. 14. CDT 8 with Earth's magnetic field data and geologic map

Fig. 15. CDT 9 with Earth's magnetic field data and geologic map

Fig. 16. CDT 10 with Earth's magnetic field data and geologic map

Fig. 17. CDT 11 with Earth's magnetic field data and geologic map

Fig. 18. CDT 12 with Earth's magnetic field data and geologic map

Fig. 19. CDT 13 with Earth's magnetic field data and geologic map

Fig. 20. CDT 14 with Earth's magnetic field data and geologic map

Fig. 21. CDT 15 with Earth's magnetic field data and geologic map

Fig. 22. CDT 16 with Earth's magnetic field data and geologic map

Fig. 23. CDT 17 with Earth's magnetic field data and geologic map

Fig. 24. CDT 18 with Earth's magnetic field data and geologic map

Fig. 25. CDT 19 with Earth's magnetic field data and geologic map

Fig. 26. Tieline CDT 101 with Earth's magnetic field data and geologic map

Fig. 27. Tieline CDT 102 with Earth's magnetic field data and geologic map

Fig. 28. Tieline CDT 103 with Earth's magnetic field data and geologic map

Fig. 29. Tieline CDT 104 with Earth's magnetic field data and geologic map

Fig. 30. Horizontal slice at 850-m elevation through three-dimensional representation of resistivity in the Cottonwood Canyon area, southern Arizona 32

Fig. 31. Horizontal slice at 1300-m elevation through three-dimensional representation of resistivity in the Cottonwood Canyon area, southern Arizona 33 
Fig. $32.10^{0} \mathrm{~W}$. dipping slice through the three-dimensional representation of resistivity in the Cottonwood Canyon area, southern Arizona

Fig. 33. Northeastward viewing of vertical slices through three-dimensional representation of resistivity in the Cottonwood Canyon area, southern Arizona 35

Fig. 34. Southeastward viewing of vertical slices through three-dimensional representation of resistivity in the Cottonwood Canyon area, southern Arizona 36

Fig. 35. Examples of airborne TEM signature of polymetallic vein deposits based on CDTs 38

\section{Plates}

Plate 1. Topographic map of the Cottonwood Canyon area, southern Arizona

Plate 2. Geologic map of the Cottonwood Canyon area, southern Arizona

Plate 3. Flightpaths over the Cottonwood Canyon area, southern Arizona

Plate 4. Magnetic anomaly map of the Cottonwood Canyon area, southern Arizona

Plate 5. Magnetic anomaly map of the Cottonwood Canyon area, southern Arizona, with superimposed geologic and mineral-resource data

Plate 6. Magnetic anomaly map of the Cottonwood Canyon area, southern Arizona, with superimposed geologic and mineral-resource data with reversed color table 


\section{Abstract}

This report tests the usefulness of airborne time-domain electromagnetic (TEM) data on three mineral-resource-related issues: (1) to test whether known mineral deposits at or near the surface display any signal in the TEM data; 2) determine whether TEM data can be used to locate bedrock concealed by basin fill; and (3) if the exposed mineral deposits display a signal in the TEM data, to determine if whether deposits are recognizable at depth in outcropping bedrock or in bedrock concealed beneath basin fill. Because Earth's total-intensity magnetic field data are also acquired with the TEM data, these data are included in the analysis.

The Cottonwood Canyon area in Santa Cruz County, Arizona, contains several polymetallic vein deposits, including those of the Tyndall, Salero, and Wrightson mining districts, all of which have had significant mineral production. Polymetallic vein deposits, which generally consist of veins of disseminated metallic minerals, commonly exhibit a response to electrical geophysical methods. Also, on the basis of other studies, the conditions that produced the polymetallic vein mineralization in the region are believed to extend offshore into the bedrock concealed by basin fill.

The polymetallic vein deposits of the Cottonwood Canyon area all display a geophysical signature in the TEM data. These deposits occur in bedrock that has, in general, a very low resistivity. The polymetallic vein deposits are associated with high-conductivity regions that extend from deep in the bedrock to the surface. These high-conductivity regions can be quite narrow $(100 \mathrm{~m})$ or quite wide $(1 \mathrm{~km})$; most are relatively narrow. Every known mineral deposit or prospect is associated with a high-conductivity feature. High-conductivity regions can also occur without an association with known mineral deposits.

Airborne TEM data appear to be able to locate the basin fill/bedrock contact beneath basin fill. The basin fill (both dry and saturated) is generally more conductive than the bedrock. The low conductivity of the bedrock ensures that no signal from the bedrock is received from under the basin fill in most places. Therefore, in most areas of basin fill, the bedrock is interpreted to be the bottom of the signal in the conductivity-depth transforms (CDTs). Although the CDTs locate the basin-fill/bedrock contact, on the basis of a comparison with a recent report, they mostly overstate its depth by a factor of at least 2.

Because CDTs based on airborne TEM data do not see into bedrock below basin fill, it is impossible to detect mineralization in the bedrock concealed by such fill. Although the geophysical signature of polymetallic vein deposits is seen at depth in outcropping bedrock, the existence of this geophysical signal does not guarantee the occurrence of polymetallic vein deposits. 


\section{Part I. Background}

\subsection{Introduction}

The USGS has used airborne time-domain electromagnetic (TEM) methods in southern Arizona to address water-resource-related issues (Bultman and others, 1999a, b). These investigations have demonstrated the ability of TEM data to differentiate the composition of basin as deep as $400 \mathrm{~m}$ below the surface. This information has proven especially useful to studies of the hydrogeologic properties of basins in the Southwest. This report tests the usefulness of TEM data on three mineral-resource-related issues: (1) to test whether known mineral deposits at or near the surface display any signal in the TEM data; (2) to determine whether TEM data can be used to locate bedrock concealed by basin fill; and (3) if the exposed mineral deposits display a signal in the TEM data, to determine whether any deposits are recognizable at depth in outcropping bedrock or in bedrock concealed beneath basin fill. Because the Earth's total-intensity magnetic field data are also acquired with the TEM data, these data are included in the analysis.

The mineral-resource potential and geology of Coronado National Forest, southeast Arizona and New Mexico (DuBray, 1996), reveal many areas of potential undiscovered mineral deposits in southeastern Arizona and New Mexico. The study area for this report is in Cottonwood Canyon (pl.1; fig.1), in the western Santa Rita Mountains and the adjacent Santa Cruz Basin.

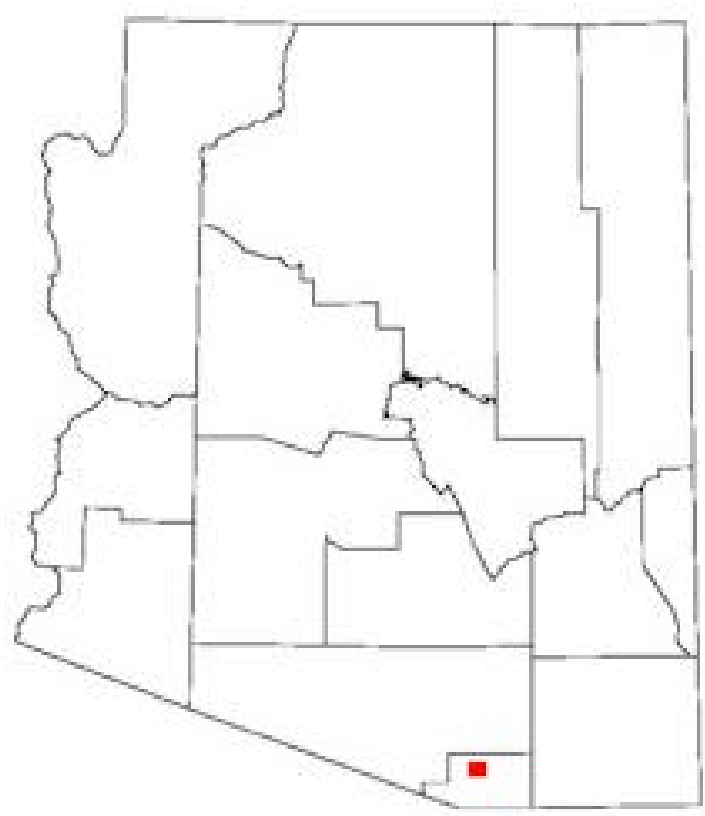

Fig. 1. Sketch map of Arizona showing location study area. See plate 1 for details. 
The Cottonwood Canyon area was chosen for several reasons. First, the Tyndall, Salero, and Wrightson mining districts are located in exposed bedrock at the western margin of the Santa Rita Mountains in or near the study area (fig. 2). Because the geologic setting of these deposits appears to continue from the exposed bedrock into the basin, conditions that produced the mineralization in the region probably extend offshore into the bedrock concealed by basin fill. Second, the Tyndall, Salero, and Wrightson mining districts are composed of polymetallic vein deposits (Bultman and Drewes, 1996), which commonly exhibit a response to electrical geophysical methods (Klein and Bankey, 1992). Third, the polymetallic vein deposits of the Tyndall mining district have had significant mineral production, indicating heavy mineralization, which may help increase the response of these deposits to an electrical signal.

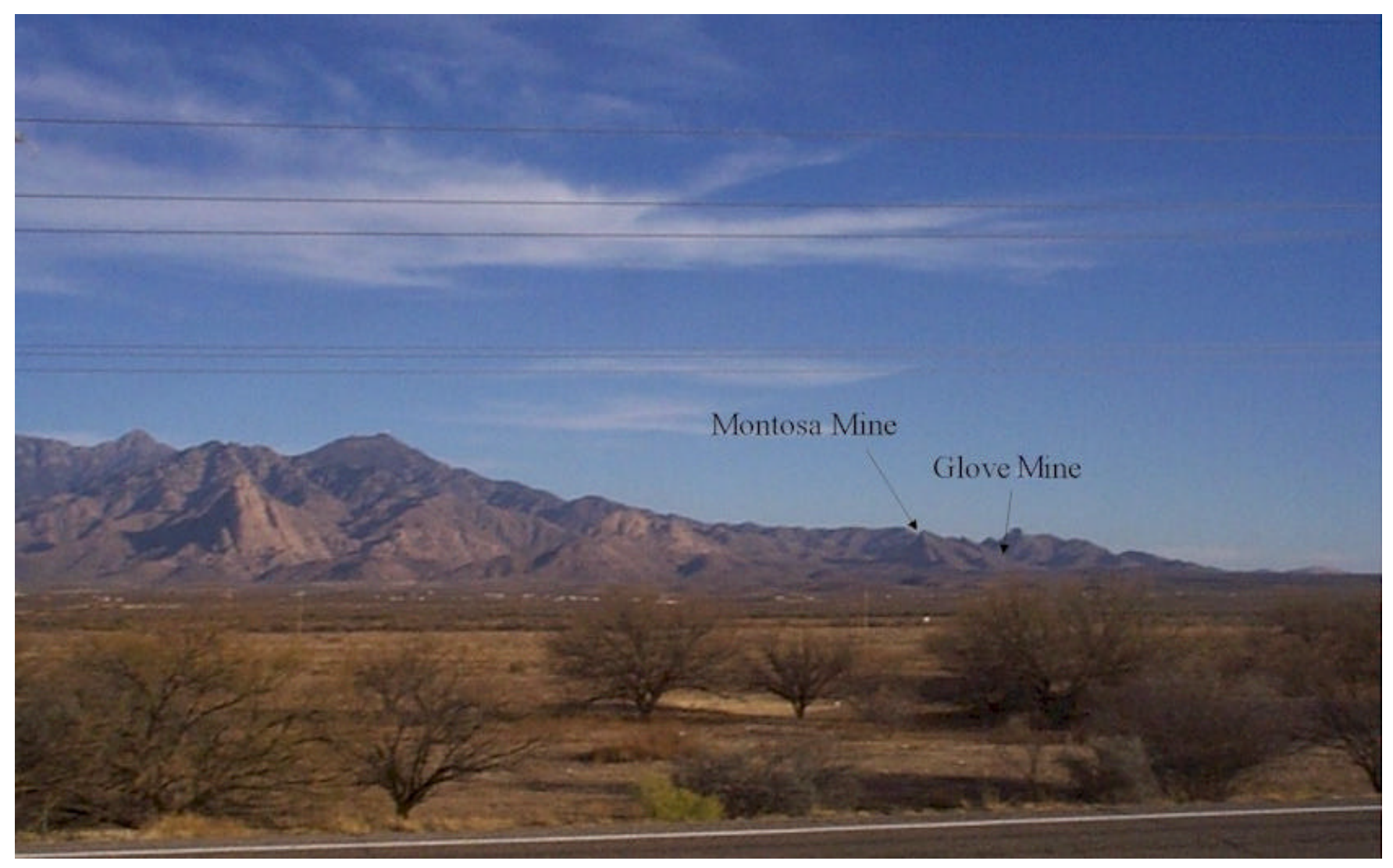

Fig. 2. Western margin of the Santa Rita Mountains, including study area (fig. 1). Photograph taken from Arizona Interstate Highway 19 in the Santa Cruz Valley. See plate 2 for mine location. 


\subsection{Geology and Mineral Resources of the Cottonwood Canyon Area}

The Cottonwood Canyon area (pl.1; fig.1) is in the southern Basin and Range Province of southeastern Arizona and northern Sonora, Mexico. This physiographic province consists of a terrain of alternating fault-bounded linear mountain ranges and sediment filled basins that began to form about 17 ma owing to dominantly east-northeast/west-southwestward directed crustal extension (Gettings and Houser, 1997). The modern topography includes northeastward and northwestward components that may have resulted from movement along the west-northwest-trending Mesozoic faults which were reactivated by Miocene extension. The study area encompasses part of the western margin of a range, the Santa Rita Mountains, and part of the eastern Santa Cruz Valley (pl. 1).

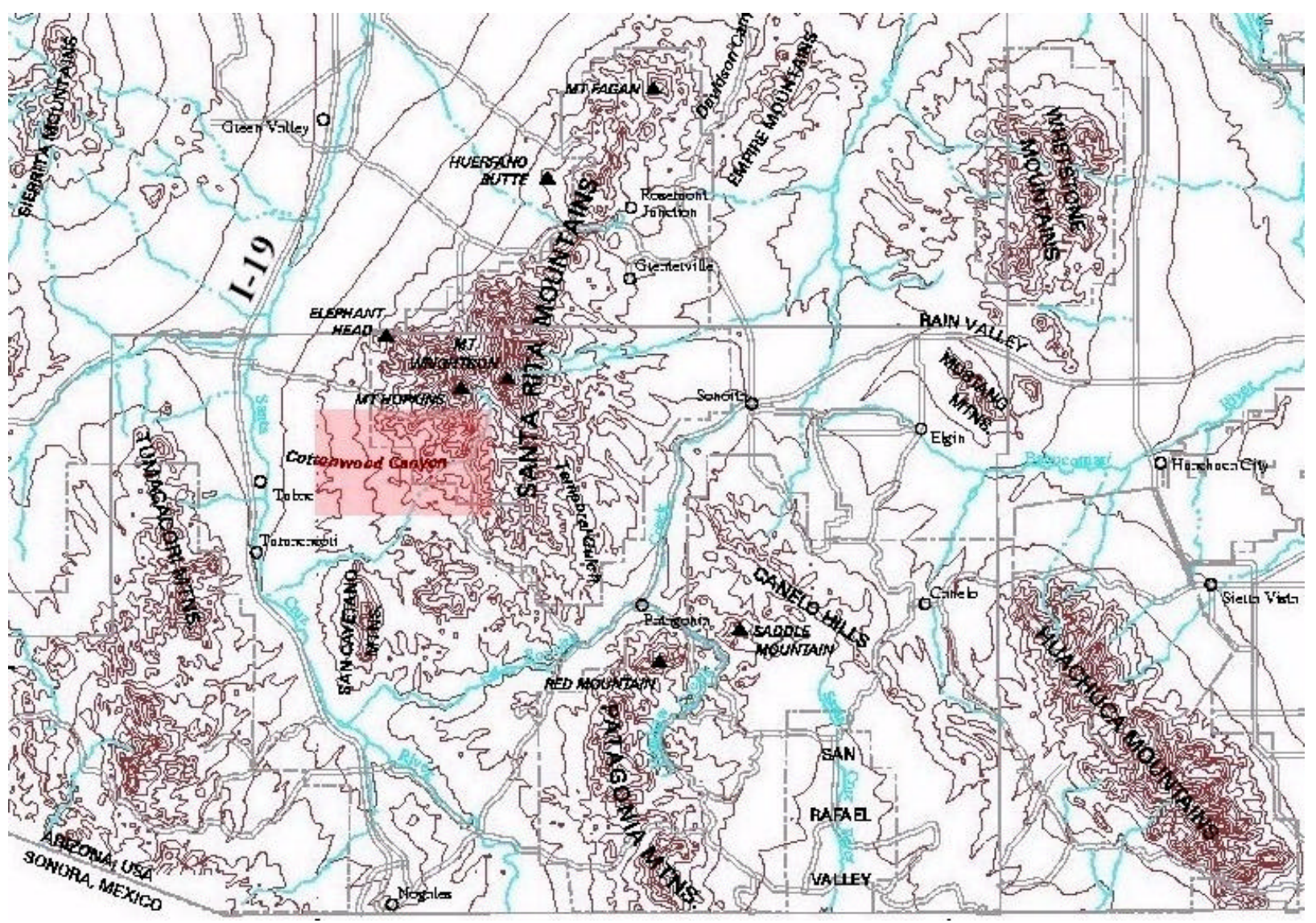

Plate 1. Topographic map of the Cottonwood Canyon area, southern Arizona.

Click here to see plate 1 at higher resolution.

The Cottonwood Canyon area in ideally suited to this study. The numerous intrusions, faults, and abundant potential host rocks make this area highly prospective for more 
mineral deposits, especially at depth. Geologic trends in the area continue northeastward, and this same prospective geologic setting may continue concealed by basin fill to the west of the Santa Rita Mountains. Bedrock depth is estimated at less than $100 \mathrm{~m}$ over those parts of the study area where bedrock is concealed by basin fill (Gettings and Houser, 1997). The Cottonwood Canyon area is home to the Tyndall, Salero, and Wrightson mining districts. Numerous mines and workings are located in this region, and many of the mines had moderate amounts of production.

The mineral deposits in the study area (pl.1; fig. 1) can be classified as polymetallic vein deposits (Bultman and Drewes, 1996). As mentioned previously, polymetallic vein deposits commonly exhibit a response to electrical geophysical methods (Klein and Bankey, 1992). The stockwork structure of the mineralization in the study area (M.E. Gettings, oral commun., 1999) may help increase the response of these particular deposits to an electrical signal. Only a general overview of the geology of the study area is presented here, focusing on the rock types and their potential as host rocks for polymetallic vein deposits. For more detailed geologic and mineral-resource information, see Drewes (1971), Bultman and Drewes (1996), and Drewes (1996).

A geologic map of the study area is shown in plate 2. The accuracy of the geologic maps that are used in this report needs to be addressed. They were digitized from the geologic map by Drewes (1996) and represent the most recent geologic map of the Cottonwood Canyon area at a scale of 1:125,000. This digitization was preliminary, because no digital version of Drewes' map has been published at this time. Thus, the accuracy of the linework has not been reviewed for conformity with U.S. Geological Survey standards. In fact, an overlay of this digital geology on the original data shows that in some places spatial-registration errors as large as $90 \mathrm{~m}$ occur, most of which are confined to mapped basin fill, though not all. In no places do these errors affect the interpretation of the relation between geology and geophysical data presented in this report. All mines are accurately located as digitized from U.S. Geological Survey 1:24,000-scale 7.5-minute topographic-quadrangle maps.

The exposed bedrock in the study area (pl. 1; fig. 1) is dominated by a large northweststriking Late Cretaceous stock (unit TKg, pl. 2) on its eastern margin. The northwestern part of this stock is mapped as the Elephant Head Quartz Monzonite (Drewes, 1971), and the southeastern part as the Josephine Canyon Diorite (Drewes, 1971). The remaining exposed bedrock consists of Tertiary intrusive rhyolite (unit Ti), Tertiary rhyolite to rhyodacite flows and tuff (unit Tr), Late Cretaceous rhyolite flows and tuff (units Kr, Krt), Late Cretaceous andesite (unit Ka), sedimentary deposits of the Early Cretaceous Bisbee formation (unit Kbu), and small Jurassic granite stocks (unit Jr) that are related to a larger intrusion to the east. Precambrian rocks also crop out, including Middle to Early Proterozoic gneiss and schist (unit YXm) and the Early Proterozoic Pinal Schist (unit $\mathrm{Xp}$ ). The entire study area is cut by northwest-trending faults and several Tertiary northwest-trending quartz-latite dikes.

A major northwest-trending fault, the Salero Fault, is the proposed south boundary for a Late Cretaceous caldera. This boundary follows the Salero Fault from the southeastern to 
the central part of the study area, where it turns northward (the northerly trending fault is unnamed). The volcanic rocks to the north and east of these faults include welded tuff (unit Krt, pl. 2) and exotic-block-member volcanic breccia (unit Ka).

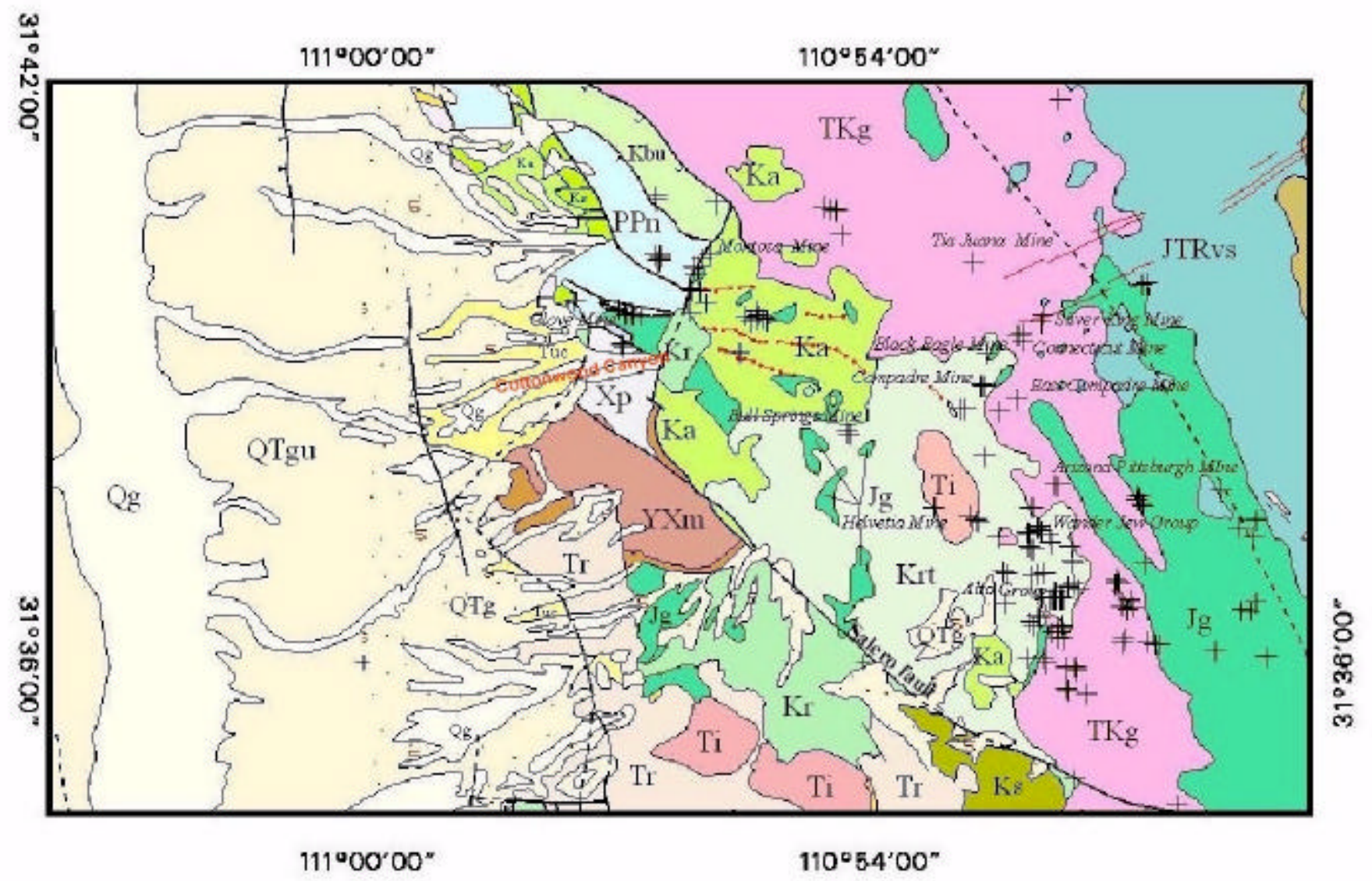

Plate 2. Geologic map of the Cottonwood Canyon area, southern Arizona

Click here to see plate 2 at higher resolution.

The large Late Cretaceous stock forming the eastern boundary of the study area (pl. 1; fig.1) is unmineralized. Where this stock is in contact with smaller plugs of Jurassic granite (unit Jg, pl. 2), the granite is unmetamorphosed. Host rocks for the polymetallic vein deposits in the study area include Lower Paleozoic sedimentary rocks such as the Horquilla limestone of the Naco group (unit PPn), which is commonly mineralized and may be present at the Glove Mine (pl. 2). Other host rocks include andesitic to dacitic flows and tuff of Late Cretaceous or Paleocene age, which are important at the Montosa and Salero Mines. Many limestone blocks in the exotic-block members of the Upper Cretaceous Salero Formation (unit $\mathrm{Ka}$ ) are probably Horquilla limestone, and where the 
andesitic host rock is mineralized, these limestone blocks may be sites of polymetallic skarn. The presence of metamorphic rocks and dikes in an area where no large intrusive bodies are exposed may indicate a concealed stock (or concealed part of the major stock to the northeast), a condition that may provide a favorable setting for occurrence of ore deposits in the subsurface.

To the east of the exposed bedrock in the study area (pl 1; fig.1) is basin fill of the Santa Cruz Basin, chiefly composed of alluvial sand and gravel deposits that form fans, terraces, and channels. The sedimentary rocks are Miocene to Holocene in age. On the basis of age and consolidation, these sedimentary rocks can be divided into two basin-fill units overlain by surficial deposits (Gettings and Houser, 1997). The lower basin-fill unit, or Nogales formation (unit Tuc, pl. 2), is probably Lower and Middle Miocene and is poorly to moderately well consolidated; the upper basin-fill unit (unit QTg or Qtgu) is Upper Miocene to Lower Pleistocene and is unconsolidated to poorly consolidated. The surficial deposits (unit Qg) include Pleistocene and Holocene alluvium of stream channels, flood plains, and terraces; these deposits are unconsolidated overall but locally well indurated.

In a previous study (Gettings and Bultman, 1993), three necessary conditions for the existence of polymetallic vein deposits were selected: 1) the presence of carbonatebearing rocks within hypabyssal depths, (2) significant fracturing of the host rocks, and (3) close proximity to felsic intrusive rocks. The temporal sequence of these conditions can be ignored here because, except in one insignificant case, throughout the study area (pl. 1, fig. 1) the carbonate rocks are all older than the felsic intrusive rocks and fracturing is everywhere at least contemporaneous with the intrusions, if not preexisting. The three conditions stated above are met by most bedrock outcrops in the study area and likely continue in the bedrock concealed by basin fill in the eastern part of the study area.

\subsection{TEM Data}

GEOTEM, the TEM data-acquisition system used in this study, is a proprietary, fully digital airborne-survey system developed and operated by Fugro Airborne Surveys. The system is consists of an aircraft, a set of transmitter and receiver coils, and instrumentation. The transmitter array consists of six horizontal-loop cables strung from nose to wing to tail to wing to nose on the outside of the aircraft for a total loop area of $232 \mathrm{~m}^{2}$ (fig. 3). This transmitter-loop array is driven by a $935 \mathrm{amp}$ (600 amp RMS) halfsine-wave time-domain signal powered by a generator-transmitter located onboard the aircraft. The received signal (consisting of the primary transmitted signal and the secondary Earth-response signal) is measured by a towed-bird detector with three mutually perpendicular coil axes. The EM receiver bird is towed behind the aircraft and about $120 \mathrm{~m}$ above the ground during flight (fig 4). The three receiver-coil axes are sensitive to horizontal conductors (Z-axis), and vertical conductors (X-and $\mathrm{Y}$-axes). The $\mathrm{X}$-axis receiver coil couples preferentially to signals arising from vertical conductors 
whose strike is parallel to the flight direction, while the y-axis responds preferentially to vertical conductors perpendicular to the flight direction (Wynn, 1999).

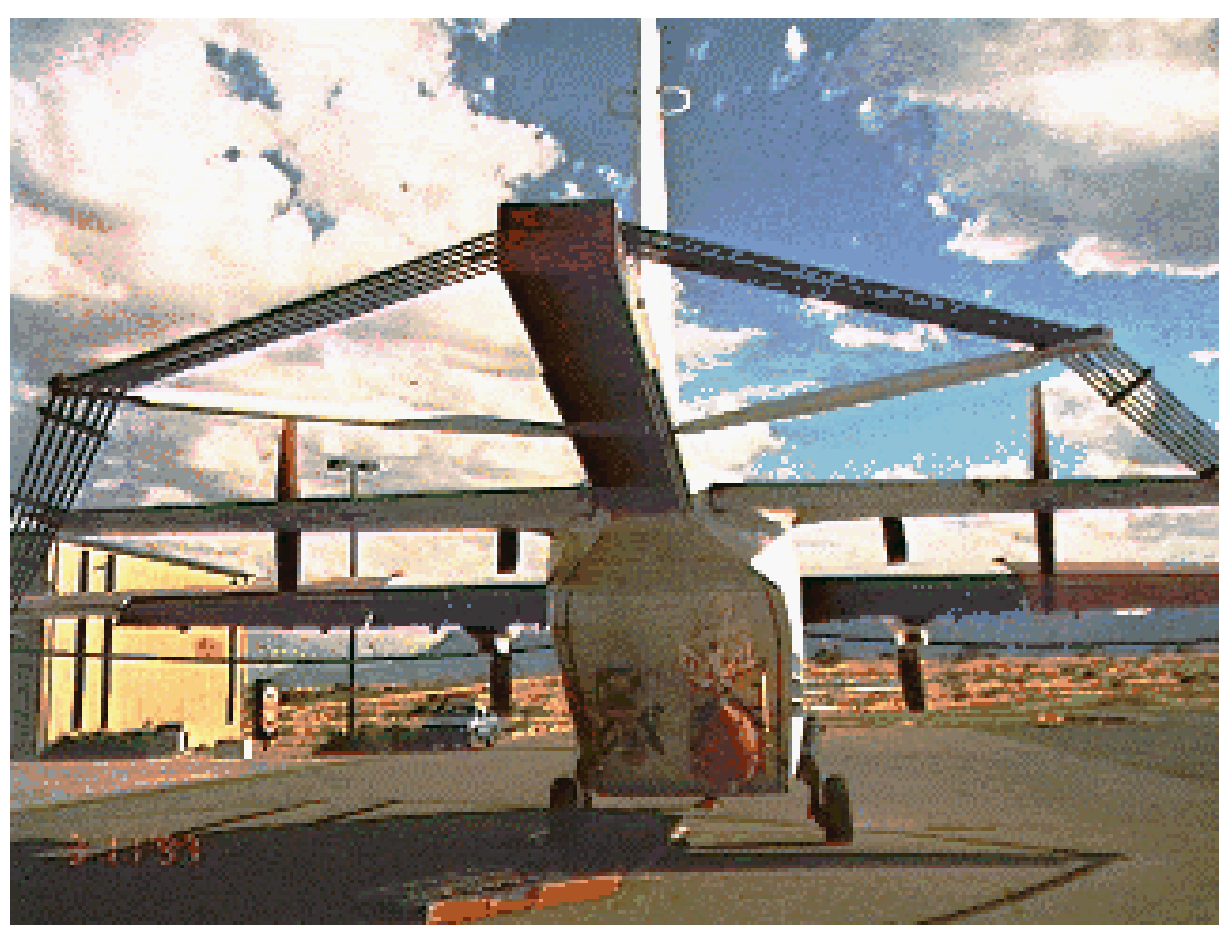

Fig. 3. Receiver "birds" and transmitting coil around perimeter of aircraft. Photograph courtesy of Jeff Wynn.

For an electromagnetic dipole, signal strength falls off as the cube of the distance between source and receiver, and so the transmitter must be maintained as close to the ground as safety permits. Effective signal-penetration depth also increases with decreasing frequency (which arrives at progressively later times after the initial impulse). Nominal flight-terrain clearance was held at $120 \mathrm{~m}$ except in steep terrain where safety made this impossible (Wynn, 1999).

The electromagnetic transmitter operated at the system minimum repetition rate of $30 \mathrm{~Hz}$, giving a pulse width of $4,036 \mu$ s to maximize penetration of the transmitted signal in an arid, conductive environment. The three-component multicoil system at this repetition rate is expected to provide conductivity information as well as structural information about the upper 150 to $400 \mathrm{~m}$ of subsurface. 


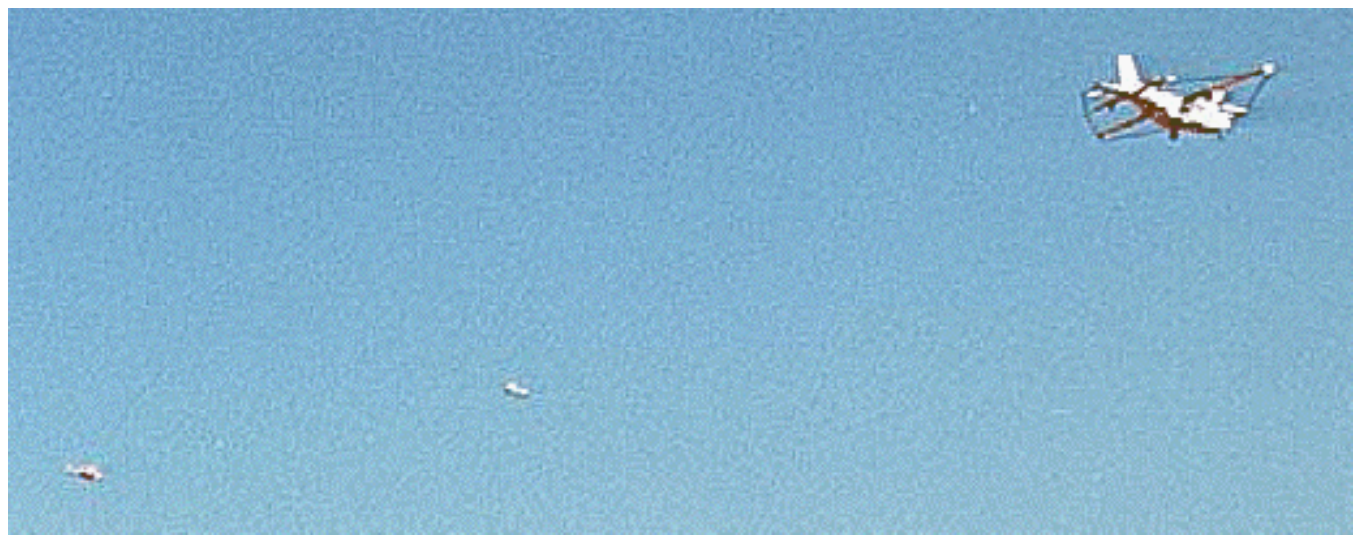

Fig. 4. GEOTEM system in operation. Photograph courtesy of Jeff Wynn.

Real-time digital processing is done on the received signal, allowing for efficient removal of the primary signal and effects of aircraft-frame flexure and vibration, a process called compensation. The different time-sampling windows of the resulting residual Earth coupling response thus have a low noise content, permitting effective use of secondary signals from substantial depths. This "gating" indicates the depth of the source; that is, longer times correlate with deeper sources (Wynn, 1999).

Conductivity Depth Transforms (CDTs) are a proprietary product derived from the gated airborne TEM data that are provided at extra cost by Fugro. The CDT-calculation process, based on a forward-modeling signal-correlation algorithm, converts the gated results to discrete conductivities as a function of depth using an infinite half-space assumption. The mathematical technique used to calculate the CDTs was described by Wolfgram and Karlik (1995). Though not technically a true inversion, the technique produces results similar to a true inversion based on the diffusion equation, yet requires much less computation. CDTs for this study were delivered to USGS as both printed output and digital grid data.

CDT data from basin fill have been compared with vertical electrical soundings (VES's) carried out in the upper San Pedro Basin and reported by Pool (1999). In general, good agreement was found between the CDT information and the VES and well logs for the first 150 m below the Earth's surface (Wynn, 1999). Bultman and Gettings (1999) also analyzed CDT accuracy by comparing the CDT values at a given location to resistivity well $\log$ data at each of nine test wells at Fort Huachuca, Arizona, in the upper San Pedro Basin about $50 \mathrm{~km}$ east of the study area (pl.1, fig. 1). For the comparison, nowhere was the CDT-calculation point more than $200 \mathrm{~m}$ from the test well. The comparison included consideration of the elevation of the water table and its effects on the CDT. To compare the CDTs to the resistivity logs, the CDT conductivity values were converted to resistivities and plotted alongside the resistivity well logs for each of the nine test wells, as shown in figures 5(a) through 5(i). 
Fig. 5 demonstrates some interesting relation between the CDTs, the well resistivity logs, and the water tables. First, the digital CDTs consistently demonstrate a higher resistivity throughout the profile than does the well log. Second, the shape of the CDTs matches the general shape of the well logs in most wells for the first $150 \mathrm{~m}$ of depth; that is, if the well logs were to be smoothed with a smoothing filter, most of their shapes would be similar to those of the CDTs. Third, for many of the test wells, the water table lies within a small distance from the upper resistivity minimum of the CDT data. This situation is not true in test wells 1 and 2, which were drilled in the highly resistive, consolidated Tertiary conglomerate Pantano Formation in the San Pedro Basin (the Pantano is similar to, considering time of deposition and amount of consolidation, the Nogales Formation [unit Tuc, pl.2] in the study area, pl. 2; fig. 1). The other test wells were all drilled in unconsolidated basin fill. The CDTs at test wells 1 and 2 display extremely high resistivities at the ground level and an upper resistivity minimum slightly below the water table in test well 1 and about $80 \mathrm{~m}$ below the water table in test well 2 . In areas of highly resistive rock at the surface, the upper resistivity minimum does not seem to correlate with the water table; its depth seems to be exaggerated. Test well 6 also displays an upper resistivity minimum below the water table, which is at about $40 \mathrm{~m}$ depth. All of the other test wells have a CDT upper resistivity minimum within one vertical data increment (11.7 $\mathrm{m}$ ) of the water table. In general, where not in the Pantano Formation (or with dry basin fill above dry Pantano?) and confined to the geographic area of the test wells, the CDT upper resistivity minimum seems to correlate fairly well with the water table, possibly owing to more conductive, less permeable deposits controlling the location of the water table. Fourth, the CDT resistivity profiles seem to correlate well with actual resistivity to about $150 \mathrm{~m}$ depth. At greater depths, conductive features seem to be conservatively estimated or underestimated.

The vertical distance of CDT profiles in basin fill of the upper San Pedro Basin (Bultman and Gettings, 1999) from the water table are plotted against and the log of resistivity in fig. 6 . The CDT profiles are calculated from the vertical conductivity data at each point. Zero on the ordinate of the plot represents the water table, positive numbers on the ordinate are above the water table, and negative numbers below it; the top of the line represents the elevation of the ground surface.

The CDT profiles show that the first minimum for many lines, the upper minimum in resistivity (down from the top), lies near the water table, a feature referred to as the upper resistivity minimum. This feature might be expected in an ideal situation. The sedimentary column is made up of many interfingering facies deposits that vary in composition and size. Moving downward toward a point where the pore space is saturated with a conductive fluid, the resistivity may tend toward a local minimum. This may also be caused by a change in the sedimentary column to a facies of predominantly clay and silt (which are more conductive than coarser grained deposits). Although many 
Figure 5(a): Test well 1

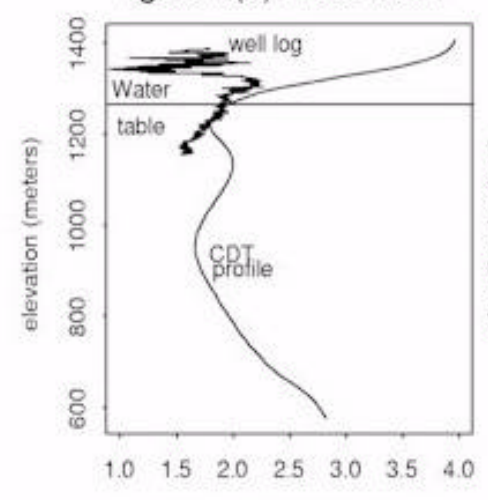

$\log 10$ of resistivity in ohm-meters

Figure 5(d): Test well 4

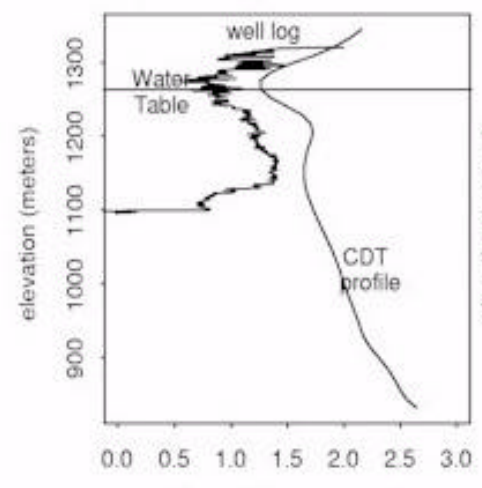

$\log 10$ resistivity in ohm-meters

Figure $5(\mathrm{~g})$ : Test well 7

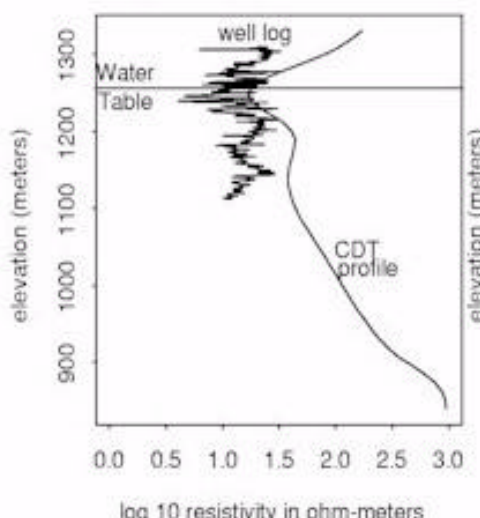

$\log 10$ resistivity in ohm-meters
Figure 5(b): Test well 2

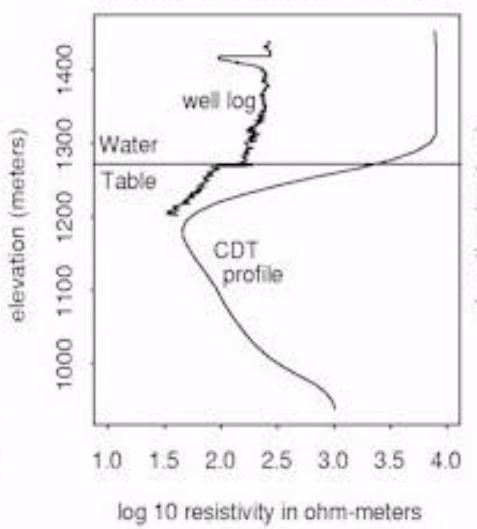

Figure 5(e): Test well 5

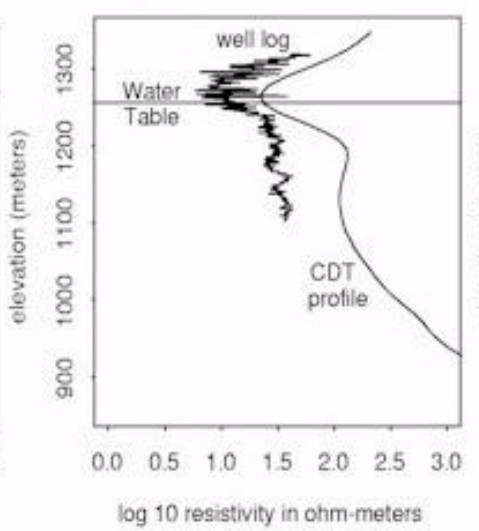

Figure 5(h): Test well 8

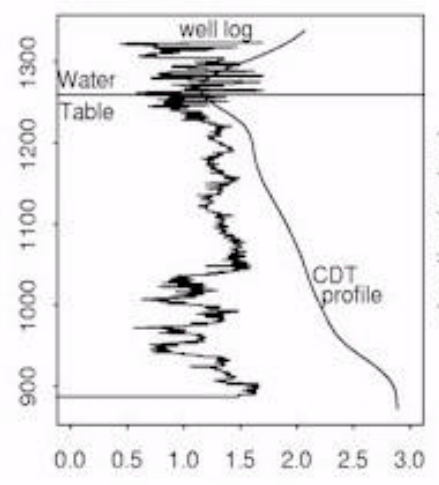

$\log 10$ resistivity in ohm-meters
Figure 5(c): Test well 3

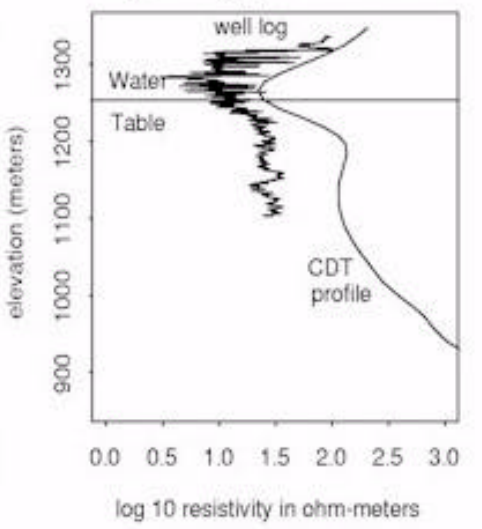

Figure 5(f): Test well 6

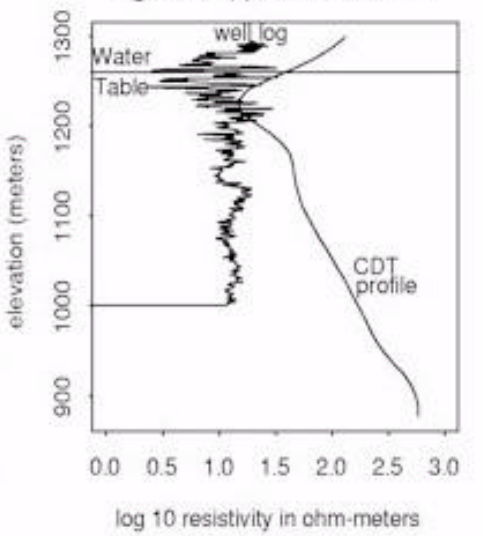

Figure 5(i): Test well 9

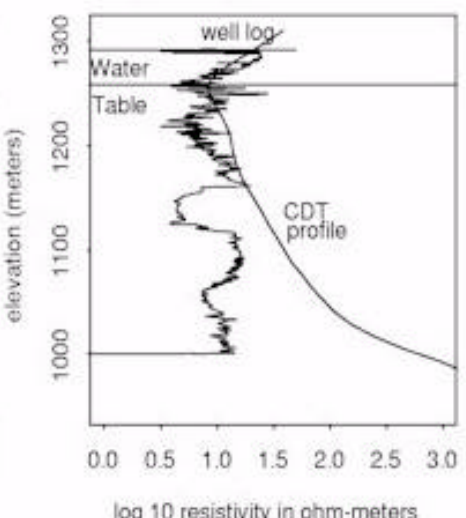

$\log 10$ resistivity in ohm-meters

Figure 5. Comparison of CDT data with downhole-resistivity logs for nine test wells at Fort Huachuca, Ariz. 
wells display a minimum resistivity at approximately $100 \mathrm{~m}$ below the water table, in general it is a second minimum that represents a lower conductor, probably a zone of clay and silt.

Fig. 6 indicates that the water table may be visible in the CDT data, but it is impossible to determine whether the minimum resistivity at the water table is due to water table or the presence of more conductive deposits (or both). In many places, silt and clay may be supporting the water table. In any case, this uncertainty is not believed to be important in the study area (pl. 1; fig. 1) because the water table in most of this area is very near the surface based on the Arizona Department of Water Resources Ground Water Site Inventory (GWSI) database (ADWR, 1999). Most water wells have depths of $6 \mathrm{~m}$ or less, possibly indicating that the vadose zone extends to or near the surface.

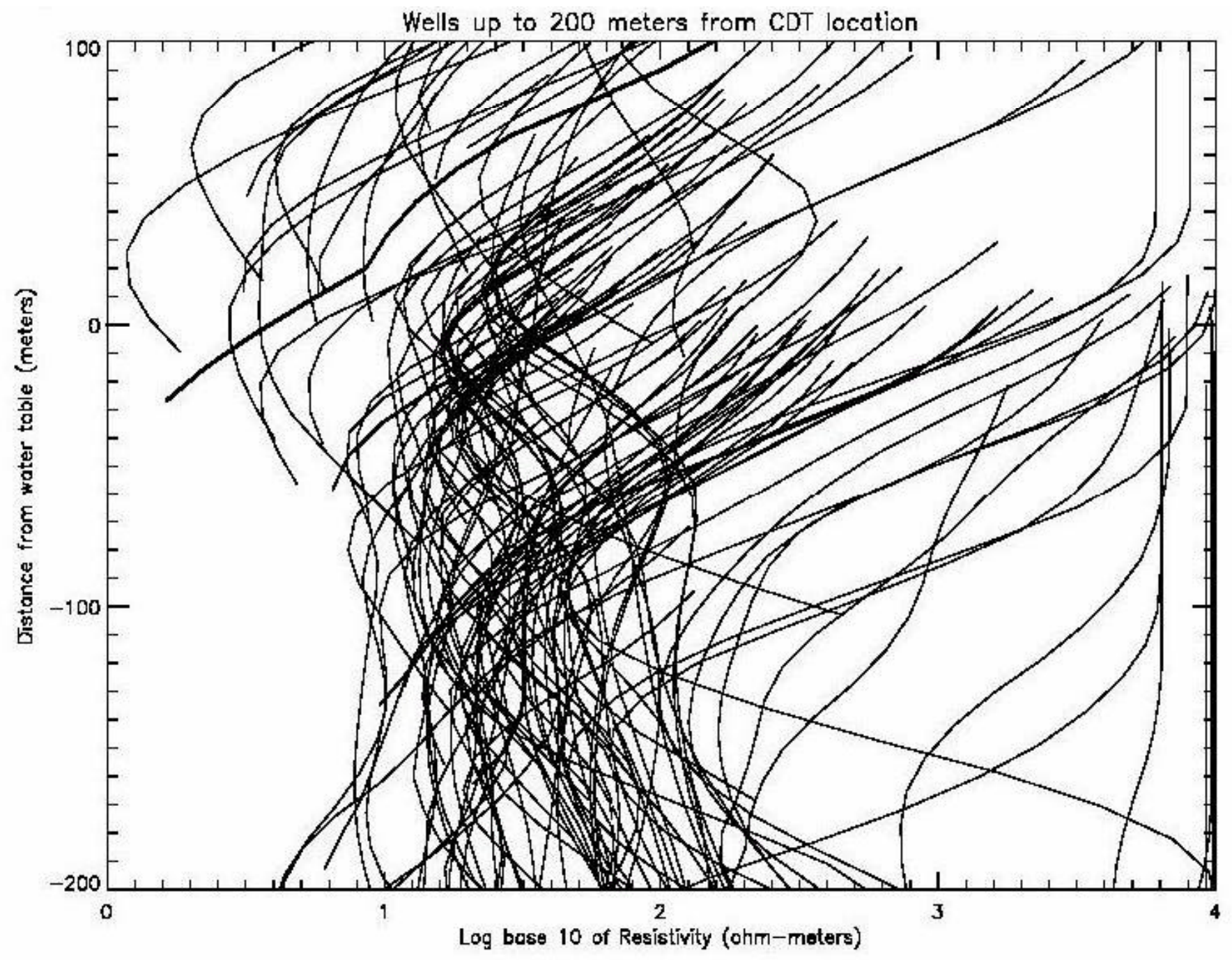

Fig. 6. Vertical distance from water table of CDT profiles in basin fill of the upper San Pedro Basin. 


\subsection{CDT Data Used in This Report}

The airborne TEM data used in this study were acquired for the USGS by Fugro in January 1998. The primary flightpaths were designed to cover about $12.6 \mathrm{~km}$ west to east over the study area (pl. 1; fig. 1) and to have a $400 \mathrm{~m}$ north-south spacing. In addition, four north-south tielines were included with a 4-km spacing. The locations of the flightpaths over the study area are shown in plate 3.

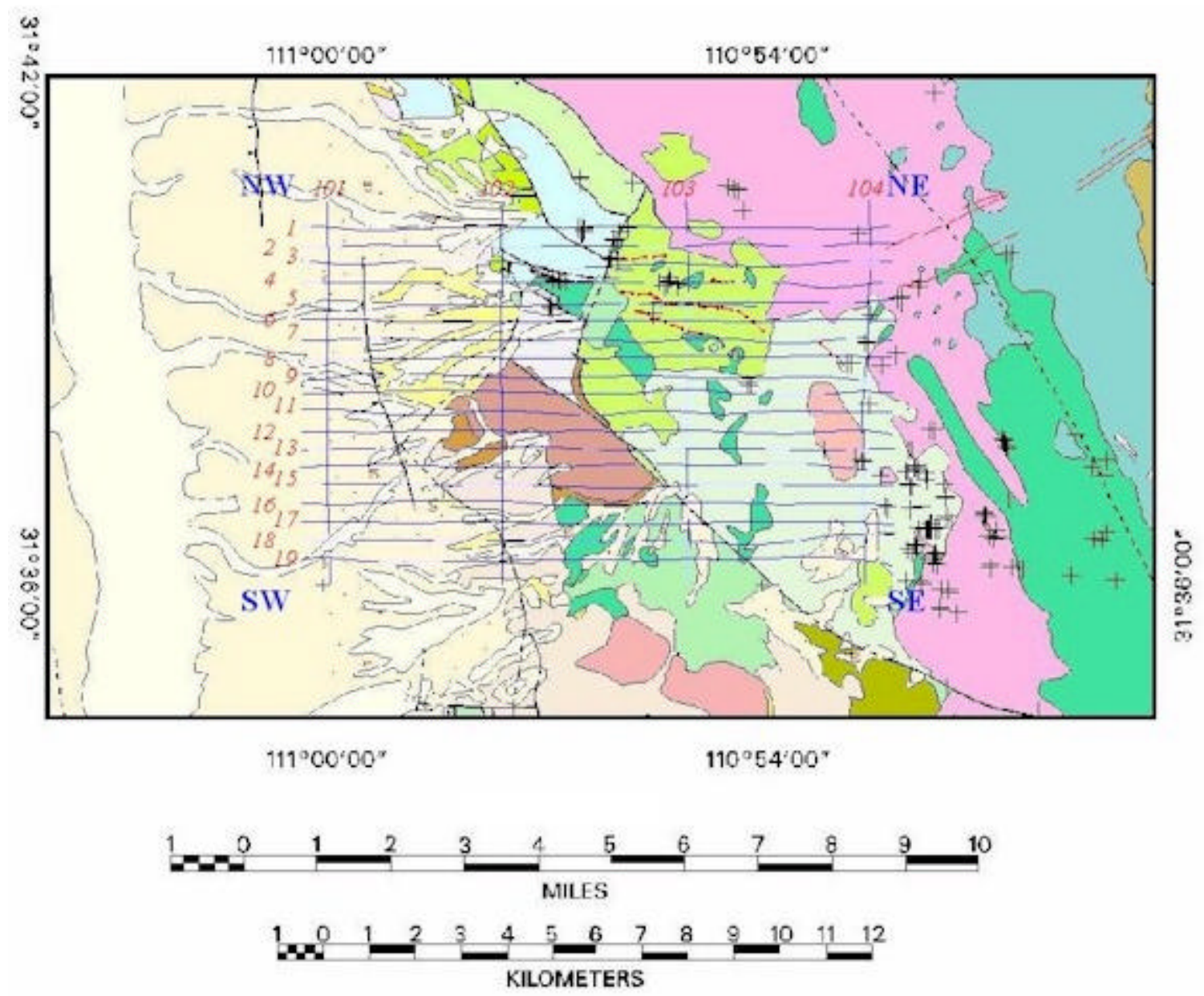

Plate 3. Flightpaths over the Cottonwood Canyon area, southern Arizona. See plate 2 for description of units.

Click here to see plate 3 at higher resolution.

The data from each flightpath were converted to a CDT by Fugro and was delivered to the USGS both as a set of printed CDTs and as digital data. Each CDT is numbered 
according to the flightpath from which the data to build it were acquired. In this study, the digital CDT data are used in two ways. First, the digital CDT grids are viewed individually, using image-analysis software. Second, the CDT grids are integrated into a three-dimensional data-cube representation of conductivity in the study area, using appropriate volume-visualization software. The data cube is labeled by the ordinal directions of its corners (NW, NE, SE, SW), and these labels are used as locational references when viewing the cube (plate 3 ).

The surface reference of the CDT grids is reprojected to the true terrain surface during CDT processing. Because the grid file must still, however, have a horizontal datum reference, the highest barometric elevation reached over the survey block is chosen as this datum. The depth of investigation is a parameter specified during CDT processing on the basis of both the depth of analysis of the TEM data and the total elevation difference in the study area. For the Cottonwood Canyon survey, the depth of investigation was chosen to be $1,700 \mathrm{~m}$. The deepest calculated conductivities lie approximately $500 \mathrm{~m}$ below the surface. The vertical relief is about $1200 \mathrm{~m}$.

In these "terrain corrected" CDT grids, the blank area between the top of the section and the first layer of real values represents air. The contour of the first layer of real values defines the ground surface and matches the topography under the region where the airborne TEM data were acquired. The CDT is calculated with 128 vertical data increments, and so, on the basis of the depth of investigation, the resulting fixed Zdirection cell size is equal to $1,700 \mathrm{~m}$ divided by 128 or $13.281 \mathrm{~m}$. The horizontal distance between data points in the CDT is based on the rate of data acquisition and the aircraft speed. In this study, the aircraft was flown as slowly as possible, and the resulting down-flightline data spacing is about $22.1 \mathrm{~m}$.

\section{Part 2. Geophysical Signature of Polymetallic Vein Deposits in the Cottonwood Canyon Area}

\subsection{Introduction}

Both airborne TEM data and Earth's total-intensity magnetic field data were used to test whether the polymetallic vein deposits of the Cottonwood Canyon area (pl. 1; fig. 1) display any geophysical signature. Because these deposits are related to felsic intrusive bodies, the associated intrusions are expected to be visible in the magnetic anomaly data. Because the mineralization in the polymetallic vein deposits of the Cottonwood Canyon area is stockwork in nature and widespread, it is expected to create a significant response in the electrical data. The faulting associated with these deposits may also produce an electrical response. 


\subsection{Magnetic Field Anomaly Map in Relation to the Geology and Polymetallic Vein Deposits of the Cottonwood Canyon Area}

Earth's total-intensity magnetic field data were acquired during the airborne TEM survey of the study area (pl. 1; fig.1). The data were analyzed to determine whether any relations exist between the Earth's magnetic field data and specific geologic features, rock types, or mineral deposits in the Cottonwood Canyon area. A magnetic anomaly map of the Cottonwood Canyon area made from data acquired during the January 1998 Cottonwood Canyon airborne TEM survey is shown in plate 4. The data range is quite large, covering more than 1,200 nT. In general, the range is larger in the exposed bedrock (eastern twothirds of map) than in the basin fill.

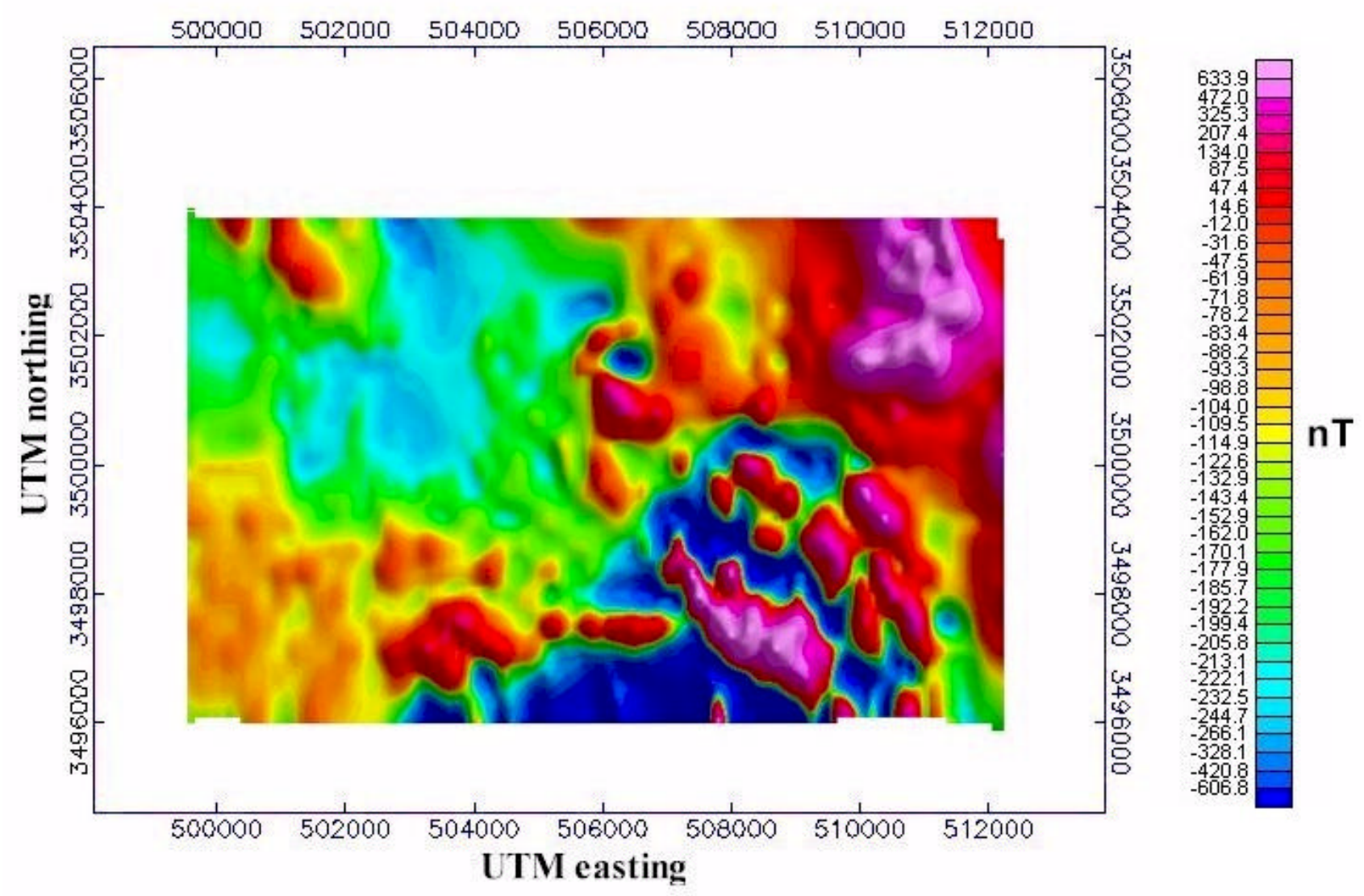

Plate 4. Magnetic anomaly map of the Cottonwood Canyon area, southern Arizona.

Click here to see plate 4 at higher resolution. 
Although the color shaded relief imaging presented in Plate 4 is useful, some geologic information must be superimposed on the magnetic anomaly map for analysis. In plates 5 and 6, the geologic map is displayed as a transparent gray-scale map superimposed on the magnetic anomaly map. Plates 5 and 6 are identical except for the color lookup tables. Because each plate displays so much information, it is difficult to devise a color lookup that shows everything. By showing both of these plates, all features are visible. The geologic map used in plates 5 and 6 includes mine and prospect information. Plates 5 and 6 were used to examine the relation between map units, mines, and anomalies of the Earth's magnetic field. Plate 2 should be consulted for specific information on the geologic map, including map-unit symbols and mine names.

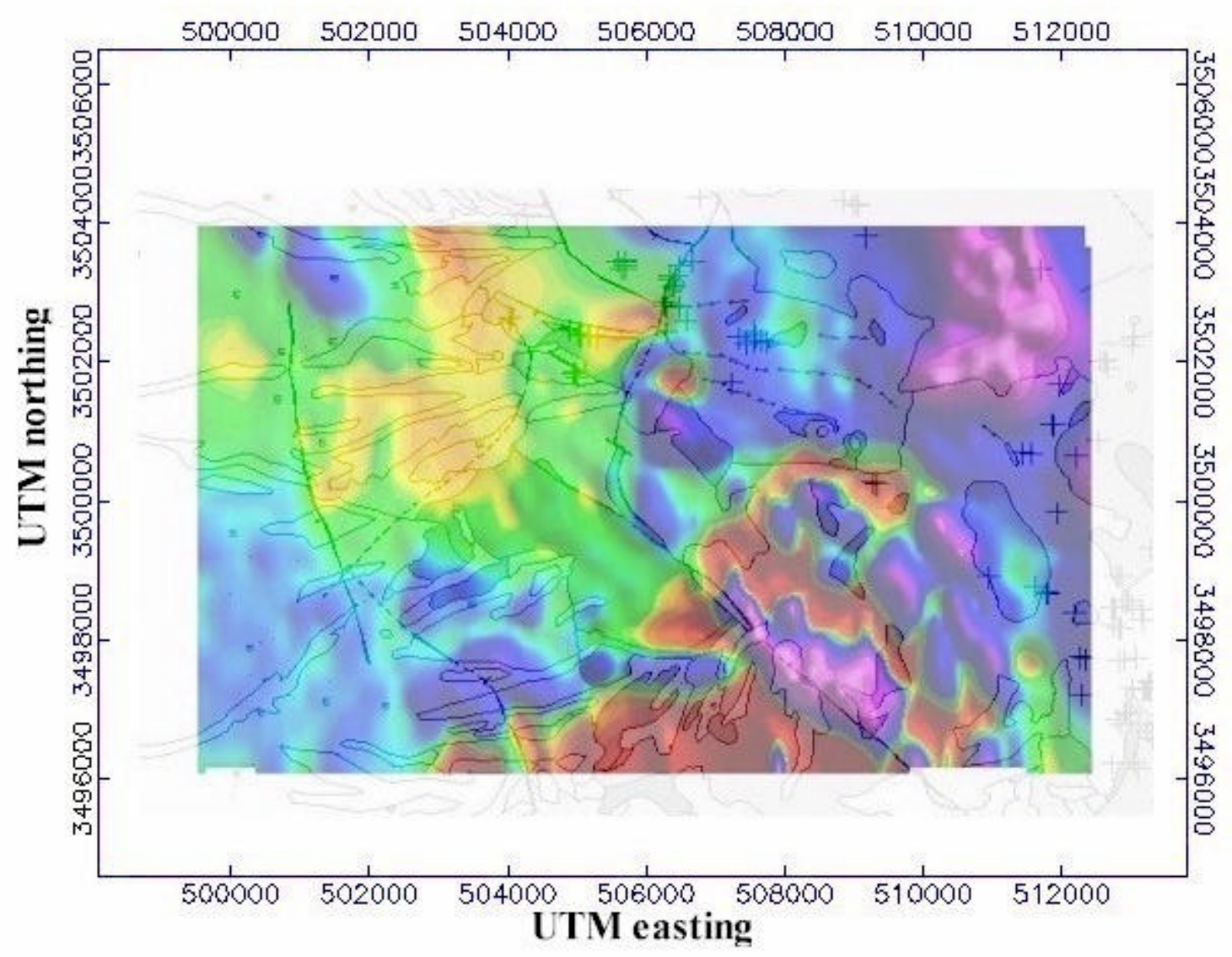

Plate 5. Magnetic anomaly map of the Cottonwood Canyon area, southern Arizona, with superimposed geologic and mineral-resource data (pluses, mines or prospects)

Click here to see plate 5 at higher resolution. 


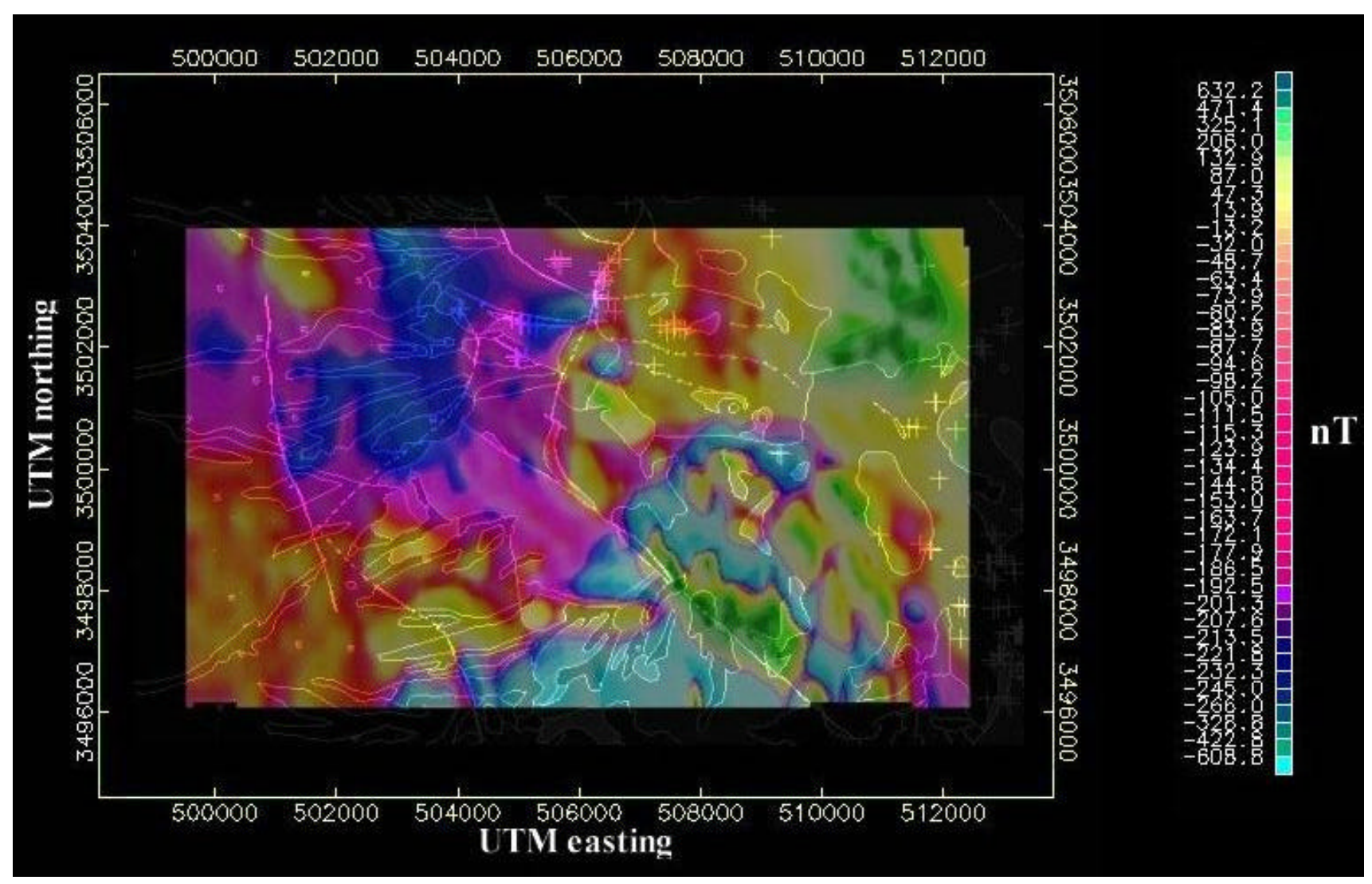

Plate 6. Magnetic anomaly map of the Cottonwood Canyon area, southern Arizona, with superimposed geologic and mineral-resource data (pluses, mines or prospects) and reversed color table (pluses, mines or prospects).

\section{Click here to see plate 6 at higher resolution.}

From plates 5 and 6, the following observations can be made, using map-unit symbols (see pl. 2 for descriptions). Within the outcropping bedrock, unit TKg has some of the highest magnetic anomaly values in the map area. The highest values correspond to the Josephine Canyon diorite, and lowest values to the Elephant Head quartz monzonite (unit $\mathrm{TKg}$ ). Units $\mathrm{Kr}$ and $\mathrm{Krt}$ appear to be reversed; these units are associated with the previously defined caldera in the Cottonwood Canyon area. Unit Ka, which is older than units $\mathrm{Kr}$ and $\mathrm{Krt}$ but also associated with the caldera, is not reversed. Unit Jg, which occurs as small stocks in the study area (pl. 1; fig. 1), displays both high and low magnetic anomaly values; it may be normally polarized in some areas and reversed in others. Units Ym and Yg have moderate to low magnetic anomaly values. These units are separated from units to the northeast by the Salero Fault, making it quite distinguishable in the magnetic anomaly map. Unit Ti has a moderate to low magnetic anomaly value, and unit Tr a high to moderate magnetic anomaly value. Unit $\operatorname{Tr}$ can be extended westward under basin fill on the basis of its magnetic anomaly value and magnetic texture. Unit PPn, limestone, is nonmagnetic except where mineralized. There 
is no magnetic indication of the many northwest-trending dikes in the region; these dikes may be rhyolytic and thus nonmagnetic.

The basin fill has low magnetic anomaly values to the north and higher magnetic anomaly values to the south. The separation of these values trends northwest. Unit YXm appears to extend northwestward under basin fill from where it crops out for several kilometers; its northeastern margin defines the Salero Fault. Units Xp and (or) PPn extend about $2 \mathrm{~km}$ northwestward under basin fill, where they are then replaced by more magnetic rocks. This fault or contact may be highly prospective for concealed mineral deposits. The southwest corner of the magnetic anomaly map (pl. 6) seems to have the same textural properties as unit $\operatorname{Tr}$ and so this unit may be concealed there.

Many of the mines and prospects are found on located magnetic gradients. Thus, combinations of steep magnetic gradients and proper host rocks are prospective areas for deep (un-exposed) polymetallic vein deposits in outcropping bedrock. Steep magnetic gradients where bedrock is concealed by basin fill have a high potential for undiscovered mineral deposits in the concealed bedrock, especially in the northwest corner of the magnetic anomaly map (pl. 6), where potential host rocks are likely to occur.

\subsection{Airborne TEM Data in Relation to the Geology and Polymetallic Vein Deposits of the Cottonwood Canyon Area}

To analyze the airborne TEM data, two approaches were used. First, CDT data for each flightline were plotted on the geologic and mine location map for that flightline. In addition, Earth's total-intensity magnetic field profiles were plotted. These data are shown for each of the 19 west-to-east flightlines and for the 4 south-to-north tielines in figures 7 through 29. Second, data from the 19 west-to-east CDTs were entered into volumevisualization software to create a three-dimensional model of conductivity in the study area (pl. 1; fig. 1).

\section{3.a Analysis Based on Individual CDTs}

Each CDT, with the accompanying Earth's total-magnetic field data, was analyzed by superimposing it on top of its flightline location on the geologic map of the Cottonwood Canyon area (pl. 2). Features in the CDTs and the flightline magnetic data could then be compared with the geology over which the data were acquired. These interpretations are shown for each of the 19 west-to-east flightlines and the 4 south-to-north tie lines in figures 7 through 29.

Interpretation is aided by the construction of numbered vertical lines, called pointers, from features in the CDTs or magnetic data to the corresponding features on the geologic map (or vice versa) (pl. 2), providing a locational tool for discussion about the 
interpretations. The pointers are divided into two groups. (1) Blue pointers are used to point out purely geologic features. The labeling scheme for blue pointers starts with the letter "G"; next comes the CDT number, and finally the feature number. Thus, the 4th geologic feature (from west-to-east) on CDT 7 is numbered G7-4. (2) Red pointers are used to point out features related to mines, prospects, or other mineral-resource features. The labeling scheme for red pointers is similar to that for blue pointers, except that the labels begin with the letter "M".

The constraints on the conductivities portrayed by the CDT's and presented above need to be considered; namely, the conductivities shown by the CDTs are probably lower than the actual conductivities of the rocks. The conductivities are even more underestimated below about $150 \mathrm{~m}$ depth. An upper conductivity maximum near the surface in the basin fill may represent the water table or may just be clay-rich sedimentary deposits. Because most water wells in the region have water levels within $6 \mathrm{~m}$ of the surface, the upper conductivity maximum will probably not be related to the water table. The vadose zone may extend to the surface in this case. Also, the vertical resolution of the CDTs is only about $13 \mathrm{~m}$. The upper conductivity maximum related to the water table may only be seen in the western portions of the survey where ground water is deeper (ADWR, 1999), if at all. Also, on the basis of previous analyses, the depth estimates of features seen on the CDTs in areas of highly resistive surface rock may be exaggerated. This relation, if it exists, has not yet been quantified.

\section{3.b General Features Visible in CDTs in the Cottonwood Canyon Area}

In the CDTs shown in figures 7 through 29, white areas contain no data and colored areas represent conductivities estimated from the airborne TEM data by the CDT calculation. The top of the data area conforms to the topography along the flightlines; areas with no data below data areas represent where the signal-to-noise (S/N) ratio in the GEOTEM system was too low for a CDT solution to be calculated, as occurs at about 150 to $400 \mathrm{~m}$ depth in areas of conductive rocks and at as much as $700 \mathrm{~m}$ depth in non-conductive rocks. In areas where no CDT data are present at all, the $\mathrm{S} / \mathrm{N}$ ratio was too low for a CDT solution to be calculated, as generally occurs only in areas of very low conductivity surface rocks. Inversions and transformations of electromagnetic data have been known to have severe errors in the estimation of depth. It is assumed in this study that the depth represented in the CDT is accurate.

Observations of the CDTs indicate that bedrock generally has a very low conductivity and outcrops of igneous and volcanic rocks have conductivities of $0.001 \mathrm{~S} / \mathrm{m}$ or less. Only units Tr, Kr, and PPn (where mineralized?) have conductivities of at least $0.01 \mathrm{~S} / \mathrm{m}$ or greater. Many of the areas of low-conductivity bedrock have higher conductivities at depth. If this feature is real, the depth may be exaggerated because of the very low conductivity material above it. 
The conductivities in the basin fill range from moderate to very high. Also, the highconductivity region extends to at least $250 \mathrm{~m}$ depth and shows no indication of lowconductivity material at depth. As a result, in most places the basin-fill/bedrock interface in the CDTs is estimated to be where the CDT calculation fails beneath areas of high conductivity rocks, that is, at the boundary where no data are visible beneath the basin fill. Some exceptions to this rule include areas where there are areas where moderate conductivity rocks underlie more conductive basin fill, possibly owing in part to the diminishing sensitivity of the CDTs to conductivity with depth or to stratigraphic changes in the basin fill. CDT 4 (fig. 10) and CDT 6 (fig. 12) are two places where bedrock may actually be seen concealed by basin fill. The low-conductivity regions that are visible beneath the highly conductive basin fill in these areas have conductivity of 0.1 to 0.001 $\mathrm{S} / \mathrm{m}$, possibly indicating indicate that only moderate conductivity bedrock is visible beneath conductive basin fill (such as unit $\mathrm{Tr}, \mathrm{Kr}$, or PPn, pl. 2). Very low conductivity bedrock simply does not allow enough electrical current to penetrate to be visible beneath basin fill.

In some areas on the western margin of the survey area, the data extend all the way to the bottom of the depth of investigation. It is assumed that in these areas, the basin fill extends deeper than the depth of investigation. On the basis of an analysis of gravity and water-well data, Gettings and Houser (1997) estimated bedrock depths in these areas at no more than $100 \mathrm{~m}$. However, very few gravity stations are located in the basin fill of the study area (pl. 1; fig. 1), and so basin depths were estimated from a 1-km gravity grid. Thus, the depth estimates are highly generalized and only represent smaller-scale features than those used in this study. In the Cottonwood Canyon area, much local vertical offset in the bedrock is invisible in the small scale study by Gettings and Houser (1997). CDT interpretations in this area imply that bedrock is locally deeper than interpreted by Gettings and Houser (1997), and they provide much information on the basin fill. Again, the reader is reminded that the vertical distances in these CDTs could be erroneous.

A recent study by Baldyga (2001) uses gravity data to model geologic cross sections in the Cottonwood Canyon area (pl. 1; fig. 1). Appendix 2 presents a comparison of Baldyga's cross sections and parts of the CDTs that lie near these cross sections. This analysis concluded that if the bottom of the CDT data represents the basin-fill/bedrock contact, then, the depths to that contact are greatly overestimated in the CDTs (by a factor of 2 or more in most places). Also, vertical offsets in the bedrock are under-expressed in the CDTs.

\section{3.c Interpretation of Individual CDTs}

To allow the reader to get a feeling for the decisions made in the interpretation process, only the first two CDTs are analyzed here; the interpretations of the other CDTs are summarized in table 1 (page 29). Each feature pointer in the CDTs (Figs. 7-29, pages 27, 28, 29 and 30) has component listed in table 1 describing the interpretation at that pointer. 
CDT 1 is shown in figure 7. All outcropping bedrock has a very low conductivity, including units PPn, Ka, and TKg (pl. 2). The low conductivity allows the TEM system to see deeper, but depth estimates may be exaggerated. Pointer G1-1 (fig. 7) is a low to high conductivity break that may indicate a concealed fault. The basin fill appears to be at least $500 \mathrm{~m}$ deep to the west of pointer G1-1, where the bottom of the depth of investigation is reached (700 $\mathrm{m}$ elevation). Lower conductivity near the surface to the west of pointer G1-1 may be due to the water table dropping away from the surface. Some water wells in this area (the far western part of the survey area) have water depths of 60 to $90 \mathrm{~m}$ (ADWR, 1999). Between pointers G1-1 and G1-2 is an area of two small bedrock highs, each with a corresponding magnetic high. The depth of basin fill is 400 to $500 \mathrm{~m}$ and the basin-fill/bedrock interface is assumed to be the bottom of the data in the CDT. Between pointers G1-2 and G1-3, there appears to be a bedrock high that reaches to within $50 \mathrm{~m}$ of the surface. Bedrock is known to crop out just to the north of this site. To the east of pointer G1-3, conductivity is high and the basin seems to be more than 300 $\mathrm{m}$ deep. At pointer G1-4, a break in conductivity signals a fault and the concealed unit PPn probably lies to the east. Pointer G1-5 is the basin-fill/bedrock contact into poorly conductive Paleozoic sedimentary deposits (unit PPn). This boundary has a strange conductivity relation that may be complicated by water entering the basin fill. Whatever the reason, the high conductivity region of basin fill seems to be pulled down at the basin-fill/bedrock interface, an interesting problem that should be attacked with a forward modeling tool. Pointer G1-6 is a fault in unit PPn and a conductivity high in the CDT that may be due to water in fractures or to mineralization.

CDT 1 intersects three mineralized areas. The first intersection occurs in a group of workings with unknown production values (pointer M1-1, fig. 7) near which is a conductivity maximum that reaches the surface. The second intersection (pointer M1-2, fig. 7) occurs at the Montosa Mine, where again, a conductivity maximum reaches the surface. This mine is located on a fault that separates the Paleozoic Naco Formation from Cretaceous andesite. A small magnetic high that also occurs between pointers M1-1 and M1-2 (fig. 7) could be a small intrusion or a cupola of a larger, deeper intrusion. The third intersection (pointer M1-3, fig. 7) occurs at the Tia Juana Mine just south of the AEM flightline from which CDT 1 was derived. CDT 1 displays a conductivity maximum directly aligned with this mine, which is also located on a steep magnetic gradient.

CDT 2 is shown in figure 8 . Pointer G2-1 is a high to low conductivity break that may indicate a concealed fault. Lower conductivity near the surface to the west may be due to the water table dropping away from the surface. Some water wells in this area (the far western part of the survey area) have water depths of 60 to $90 \mathrm{~m}$ (ADWR, 1999). The bottom of the TEM data to the west of pointer G2-1 is interpreted as the basinfill/bedrock contact. A horst appears to occur between pointers G2-1 and G2-2. This area also corresponds to a magnetic high, probably the same feature that occurs between pointers G1-2 and G1-3 (fig. 7) in CDT 1, $400 \mathrm{~m}$ to the north. This feature may reach the surface in this area. To the east of pointer G2-2, conductivity is high, and basin depth seems to be about $250 \mathrm{~m}$. At pointer G2-3 a break in conductivity signals a northwesttrending fault and the concealed unit PPn (pl. 2) lying to the east. Pointer G2-4 is the 
basin-fill/bedrock contact with poorly conductive Paleozoic sedimentary deposits (unit $\mathrm{PPn})$. To the east of pointer $\mathrm{G} 2-4$ the $\mathrm{S} / \mathrm{N}$ ratio of the TEM system is very low, and the solution to the transformation can be calculated in only a few places. The $\mathrm{S} / \mathrm{N}$ ratio is higher in areas of higher conductivity bedrock.

Total-

intensity

Earth's

magnetic

field

CDT

White areas have no data
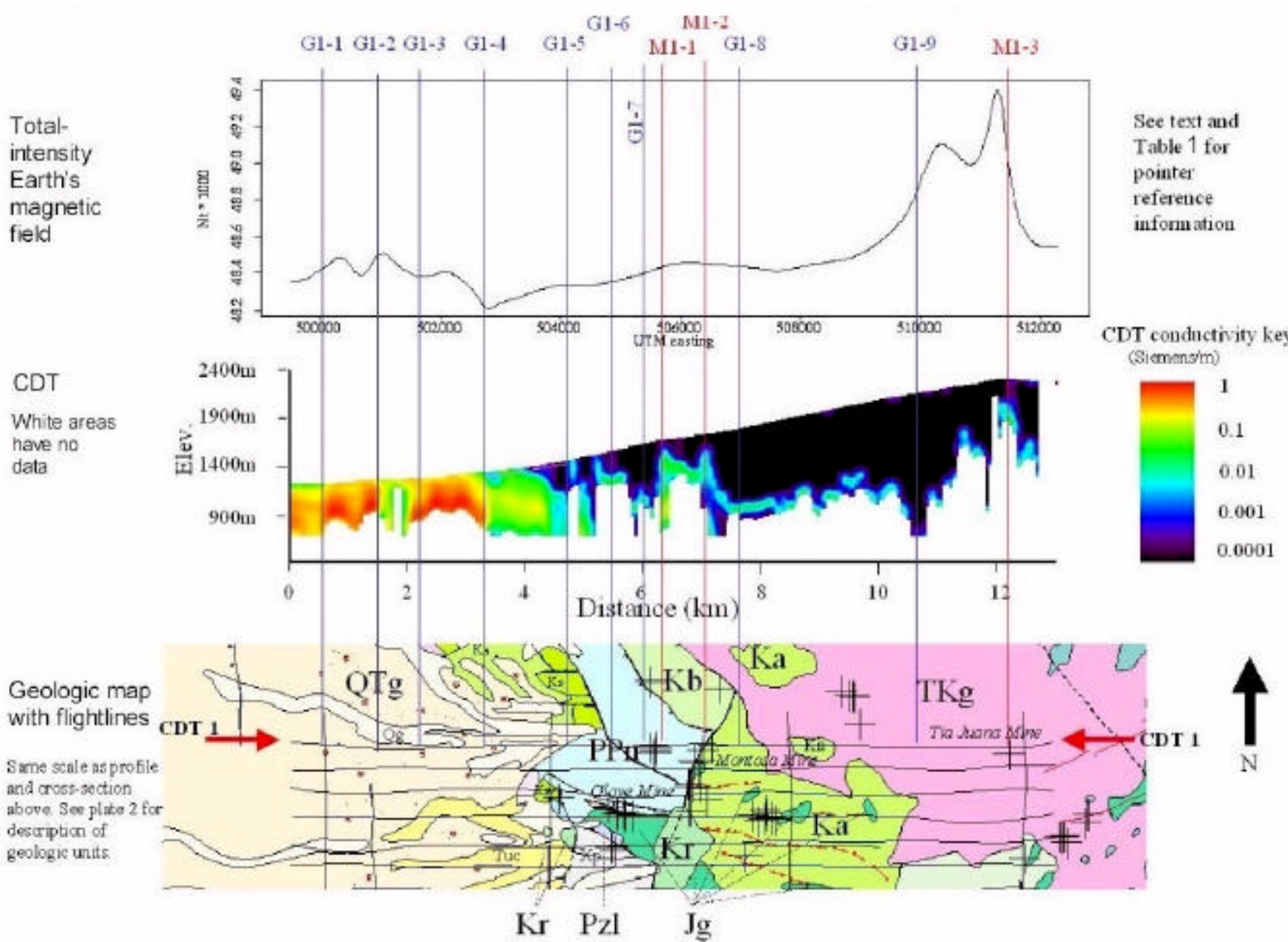

Figure 7. CDT 1 with Earth's magnetic field data and geologic map. Figure 7 is also available at a higher resolution on page 29.

CDT 2 intersects two mineralized areas. The first intersection occurs in a group of workings associated with the Montosa Mine (pointer M2-1, fig. 8), near which is a conductivity maximum that reaches the surface and extends eastward for some distance. These conductivity highs that reach the surface to the east of pointer M2-1 are not associated with any known mineralization and seem to be associated with a small magnetic high. The second intersection occurs in a mineralized area (pointerM2-2, fig. 8) 
near some workings at the east end of the flightline. Again, a conductivity maximum reaches the surface in this area. The workings at pointer M2-2 are also associated with a steep magnetic gradient.

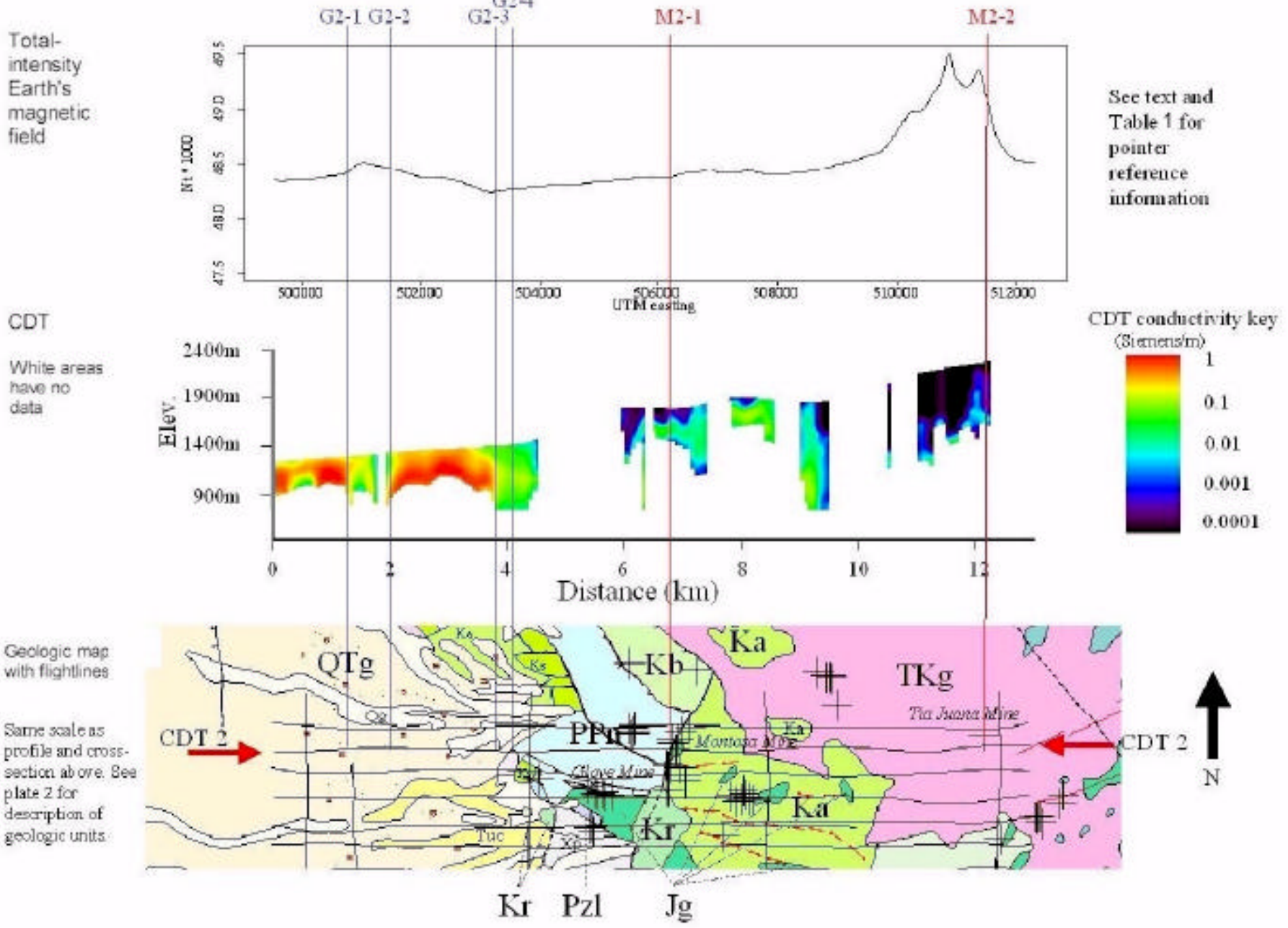

Figure 8. CDT 2 with Earth's magnetic field data and geologic map. Figure 8 is also available at a higher resolution on page 29 . 
The interpretation of the other CDTs are summarized in table 1. Table 1 and all of the figures (7 through 29) are accessible below by clicking on each link:

$\underline{\text { Table 1. Pointer references of geologic and mineral related features to CDTs, Earth's }}$ magnetic field data, and to a geologic map

Fig. 7. CDT 1 with Earth's magnetic field data and geologic map

Fig. 8. CDT 2 with Earth's magnetic field data and geologic map

Fig. 9. CDT 3 with Earth's magnetic field data and geologic map

Fig. 10. CDT 4 with Earth's magnetic field data and geologic map

Fig. 11. CDT 5 with Earth's magnetic field data and geologic map

Fig. 12. CDT 6 with Earth's magnetic field data and geologic map

Fig. 13. CDT 7 with Earth's magnetic field data and geologic map

Fig. 14. CDT 8 with Earth's magnetic field data and geologic map

Fig. 15. CDT 9 with Earth's magnetic field data and geologic map

Fig. 16. CDT 10 with Earth's magnetic field data and geologic map

Fig. 17. CDT 11 with Earth's magnetic field data and geologic map

Fig. 18. CDT 12 with Earth's magnetic field data and geologic map

Fig. 19. CDT 13 with Earth's magnetic field data and geologic map

Fig. 20. CDT 14 with Earth's magnetic field data and geologic map

Fig. 21. CDT 15 with Earth's magnetic field data and geologic map

Fig. 22. CDT 16 with Earth's magnetic field data and geologic map

Fig. 23. CDT 17 with Earth's magnetic field data and geologic map

Fig. 24. CDT 18 with Earth's magnetic field data and geologic map

Fig. 25. CDT 19 with Earth's magnetic field data and geologic map

Fig. 26. Tieline CDT 101 with Earth's magnetic field data and geologic map 
Fig. 27. Tieline CDT 102 with Earth's magnetic field data and geologic map Fig. 28. Tieline CDT 103 with Earth's magnetic field data and geologic map Fig. 29. Tieline CDT 104 with Earth's magnetic field data and geologic map 


\subsection{Three-Dimensional Interpretation of Airborne TEM Data in Relation to the Geology and Polymetallic Vein Deposits of the Cottonwood Canyon Area}

The digital CDT data from flightlines 1 through 19 (pl. 3) can be used to examine features and trends in the airborne TEM data in three dimensions. Each CDT was processed for differences in the starting and ending points of each flightline and for differences in the down flightline distances between sample points. The flightlines were all essentially parallel, and so no correction for differing flightline direction was necessary. The processed data were then inputted into three-dimension visualization software that allows the resulting volume to be visualized from any perspective.

Visualizations of the three-dimensional data cube are plotted with a reverse-color scale from the CDTs shown in figures 7 through 29. This reversed-color scale corresponds to a resistivity scale, wherein the regions of highest resistivity (lowest conductivity) are shown in red and the regions of lowest resistivity (highest conductivity) are shown in dark blue. The explanation in these figures is based on resistivity, which is simply the inverse of conductivity. Values with missing data are now set to black instead of white, because the three-dimensional visualization software uses a black background. To be transparent in the three-dimensional visualizations, the missing data must be black.

Figure 30 displays a horizontal slice through the data cube at an $850 \mathrm{~m}$ elevation viewed northeastward. The entire east half of the data cube lacks conductivity data in much of the exposed bedrock, as is visible in this slice. These data are missing because several CDTs had too low a $\mathrm{S} / \mathrm{N}$ to calculate a solution in that area. The striping is due to the volumevisualization software interpolating (to the north or south) to the next data value, which is zero if no data are present. Because of this problem, the data cube is less useful in some areas where bedrock crops out.

Figure 30 shows highly conductive water-filled sedimentary deposits near the bottom of the basin fill as blue regions in the west third of the data cube. Lateral variations in conductivity are shown as color variations in these blue regions: they are related to the sand-versus-clay and silt contents of the sedimentary deposits. Regions where the horizontal slice intersects bedrock in the basin fill show up as areas with no data (black) interspersed in the conductive sedimentary deposits. The green areas (labeled "bedrock?") within the basin fill represent regions where moderately conductive bedrock (such as units $\mathrm{Tr}, \mathrm{Kr}$, and PPn, pl. 2) are visible beneath the basin fill. The "main range fault" is plotted where conductivities drastically decrease. Although the actual range fault is probably a system of several faults, it is visible here as a dramatic decrease in conductivity and is simply referred to as the "main range fault". Thus, this term indicates where the transition occurs from basin fill to bedrock as revealed in these data. Areas to the east of this fault represent bedrock. Close to the fault, some bedrock is concealed by basin fill. One such area, where map unit PPn is concealed by shallow basin fill, is shown in figure 30 . 


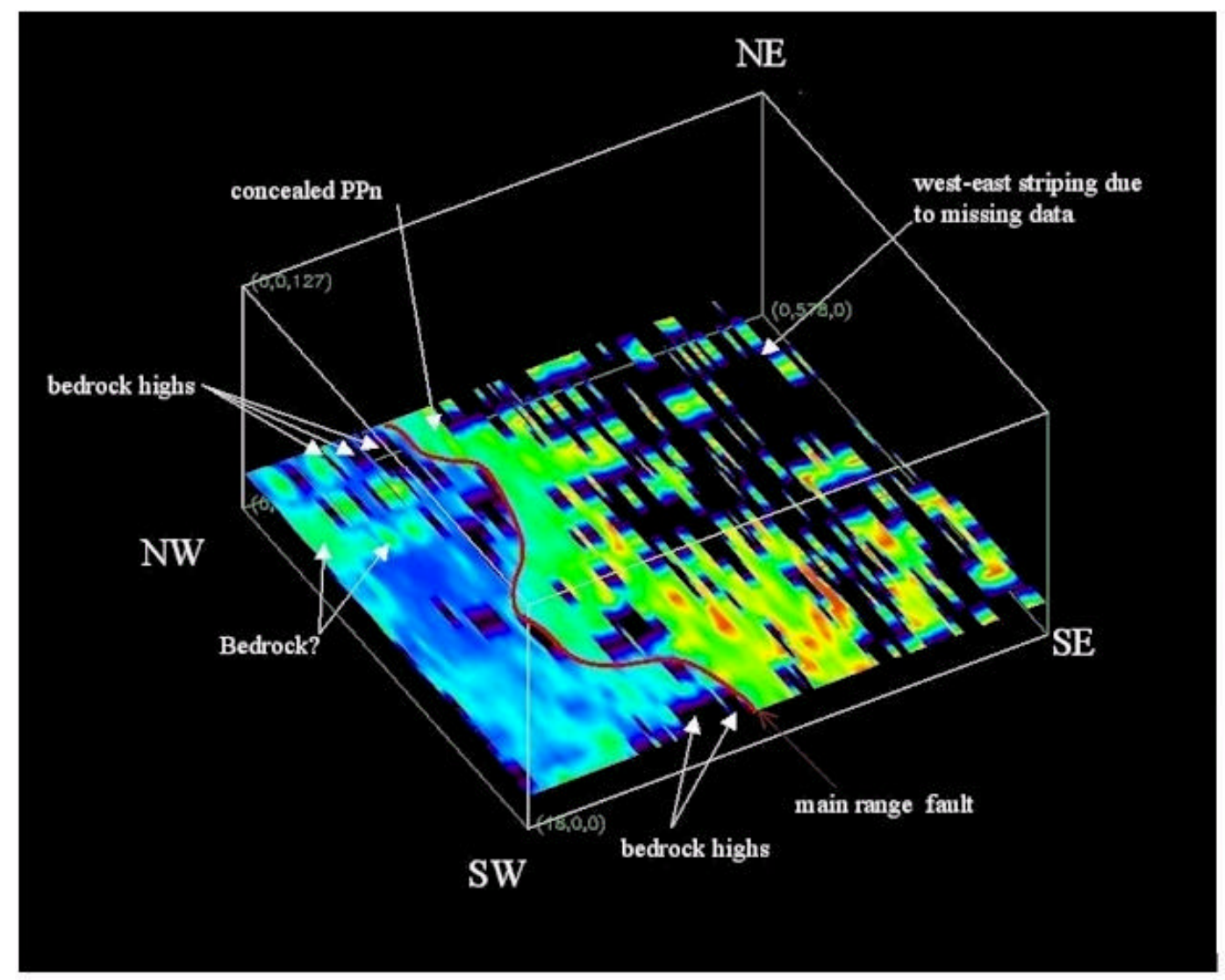

Extent of axes:

SW to SE: $12.6 \mathrm{~km}$ NWW to SW: $8.5 \mathrm{~km}$ $\mathrm{z}$ axis: $\quad 1.7 \mathrm{~km}$

Resistivity Key (in $\log _{10}$ ohm-m)

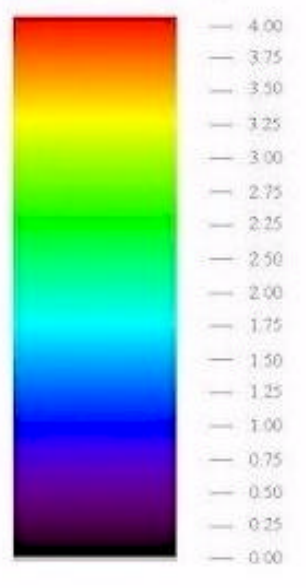

Figure 30. Horizontal slice at $850 \mathrm{~m}$ elevation through the three-dimensional representation of resistivity in the Cottonwood Canyon area, southern Arizona. Data-cube corner labels based on direction and shown in plate 2 .

Figure 31 shows a horizontal slice through the data cube at $1300 \mathrm{~m}$ elevation, viewed northeastward. It shows many of the same features seen in figure 30. The western part of the data is missing because the slice in this area is above ground level. The Salero Fault is visible in the data, and its location is shown in figure 31 . The highly resistive units YXm and Krt make up the large red area in the southeastern part of the data cube. The moderately resistive units Tr and Kr occur to the south of units YXm and Krt. The very low resistivity (high conductivity) area near the southwest corner of figure 31 marks the bottom of basin fill on top of bedrock highs. These regions are also visible in CDTs 18 and 19 (figs. 24 and 25). 


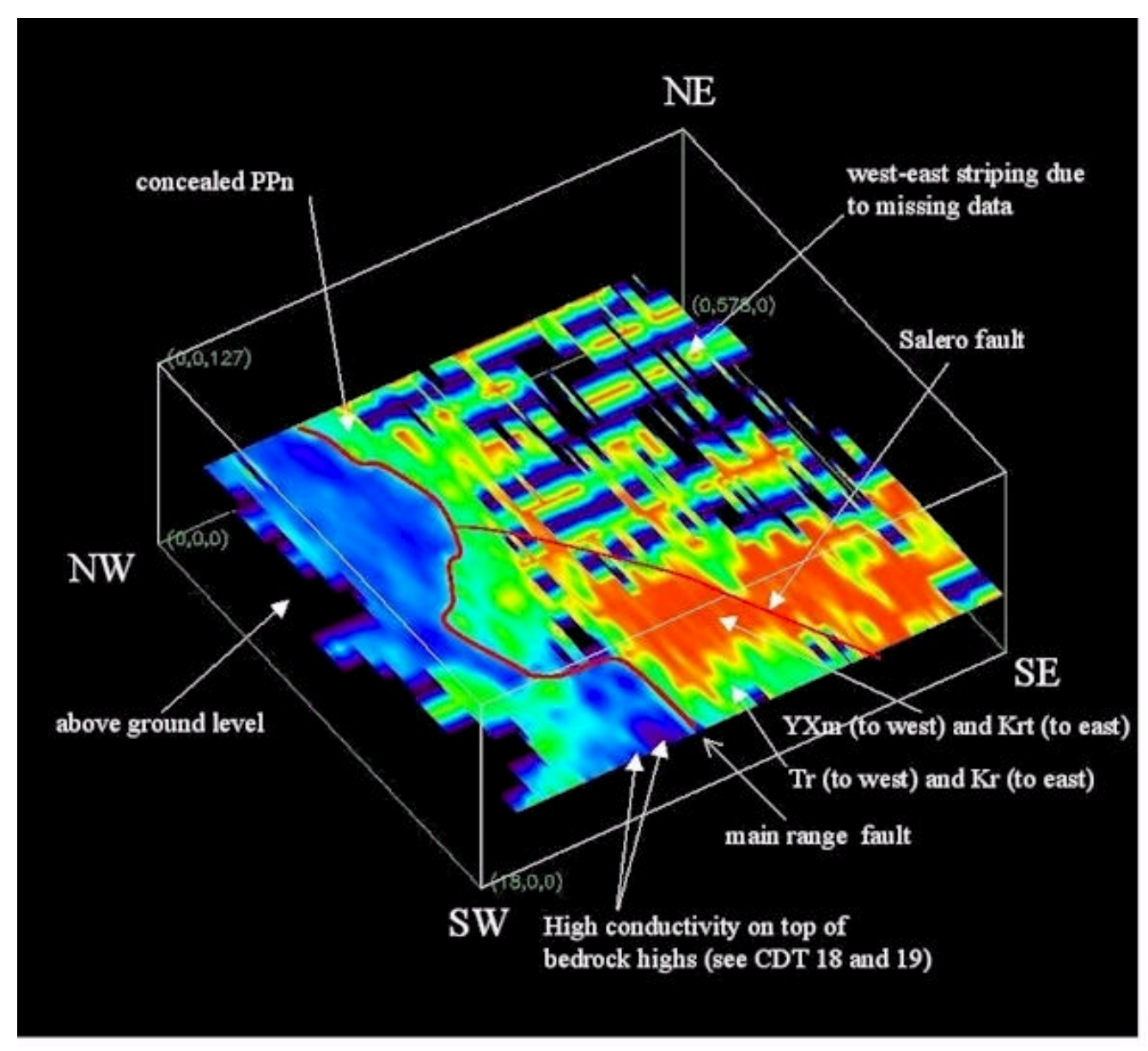

Extent of axes:

SW to SE: $12.6 \mathrm{~km}$ NW to SW: $8.5 \mathrm{~km}$ $\mathrm{Z}$ axis:

$1.7 \mathrm{~km}$

Resistivity Key (in $\log _{10} \mathrm{ohm}-\mathrm{m}$ )

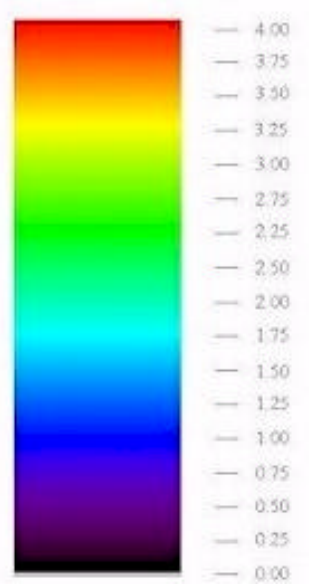

Figure 31. Horizontal slice at $1300 \mathrm{~m}$ elevation through the three-dimensional representation of resistivity in the Cottonwood Canyon area, southern Arizona. Data-cube corner labels based on direction and shown in plate 2 .

Fig. 32 shows a slice through the data cube that is a plane dipping about $10^{\circ} \mathrm{W}$., viewed northeastward. This dip makes up for some of the change in elevation of the ground surface over the area. The slice is about $100 \mathrm{~m}$ below the ground surface in the basin-fill part of the study area (pl. 1; fig. 1) and somewhat deeper in the exposed-bedrock part of the Cottonwood Canyon area. Several east-west and north-south lineaments visible in the northern part of the data cune and are highlighted with red lines. Although east-west anomalies are due to the east-westward direction of the flightlines, this does not explain the entire anomaly. The green regions labeled "bedrock highs" in figure 30 seem to be controlled by east-west lineaments.

Mine and prospect locations are also shown in figure 32. No correlations between the mine and prospect locations and resistivity values in the data can be made. The poor quality of the data, when viewed in this manner (that is, in horizontal or near-horizontal slices), contributes to this problem. 


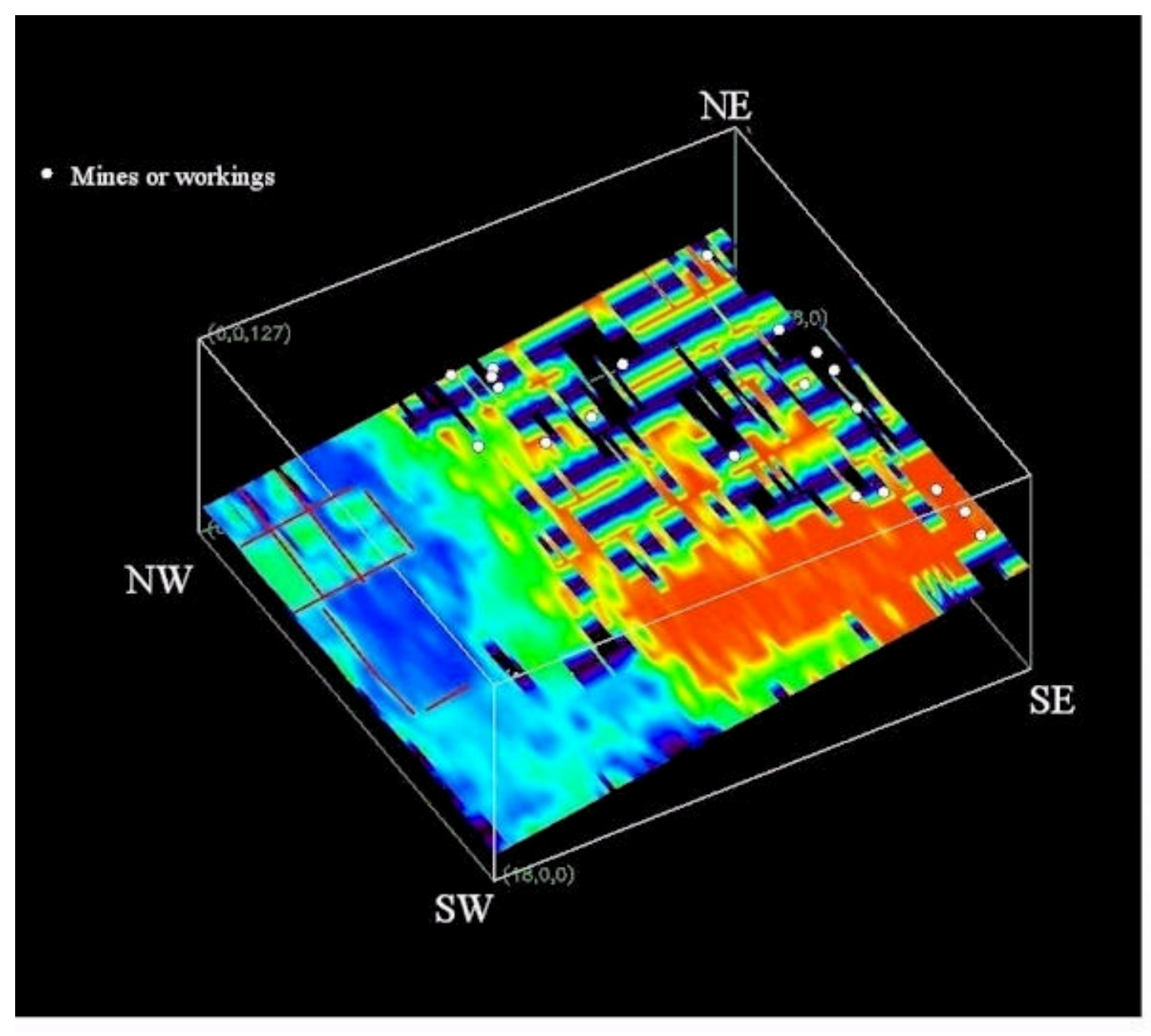

Extent of axes:

SW to SE: $12.6 \mathrm{~km}$ NW to SW: $8.5 \mathrm{~km}$ $\mathrm{z}$ axis: $1.7 \mathrm{~km}$

Resistivity Key (in $\log _{10} \mathrm{ohm}-\mathrm{m}$ )

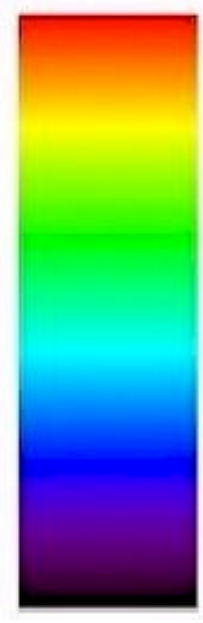

Figure $32.10^{\circ}-\mathrm{W}$.-dipping slice through the three-dimensional representation of resistivity in the Cottonwood Canyon area, southern Arizona. Data-cube corner labels based on direction and shown in plate 2 .

Figure 33 shows several east-to-west vertical slices through the data cube. Given that the data cube is composed of only 19 east-to-west flightlines, only east-west vertical slices can be displayed in any useful manner. Slices with any north-south component lack data in that direction. This display method, which allows an analysis of features on many CDTs at once, is useful for highlighting the spatial relation between features.

Many of the north-south features in the northwestern part of the data cube that are shown in figure 32 are also visible here, including a south plunging horst, and two northwesttrending bedrock highs (in the basin fill). The features can be traced northwestward into the Santa Rita Mountains. 
In this type of view, it is easy once again to pick out many of the narrow conductivity highs in the exposed bedrock that are correlated with the mines and prospects in the area, several of which are shown in figure 33.

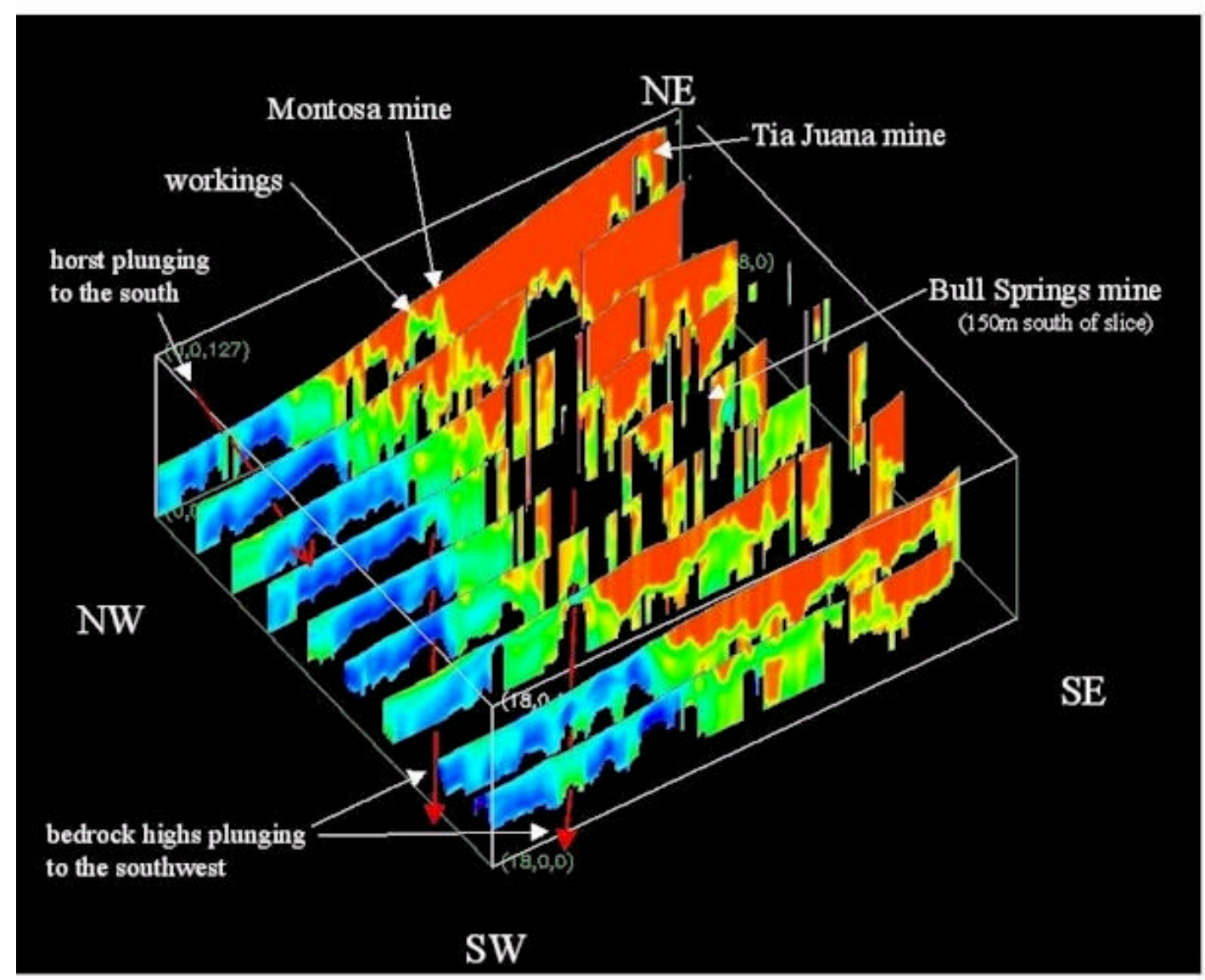

Extent of axes:

SW to SE: $12.6 \mathrm{~km}$ NW to SW: $8.5 \mathrm{~km}$ zaxis: $1.7 \mathrm{~km}$

Resistivity Key (in $\log _{10} \mathrm{ohm}-\mathrm{m}$ )

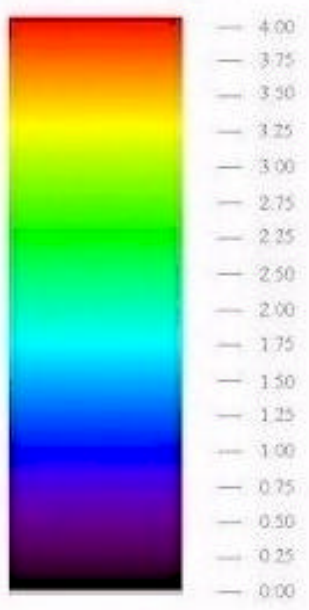

Figure 33. Northeastward view of vertical slices through the three-dimensional representation of resistivity in the Cottonwood Canyon area, southern Arizona. Data-cube corner labels based on direction and shown in plate 2 .

Figure 34 shows several west-to-east vertical slices through the data cube, viewed southwastward. The change in viewing direction helps to discern features that were not easily visible in previous figures. One conspicuous feature is a northwest-trending fault in the bedrock that extends to a bedrock high in the basin, as well as a fault that is likely one of the several faults that act as a range front-fault. 


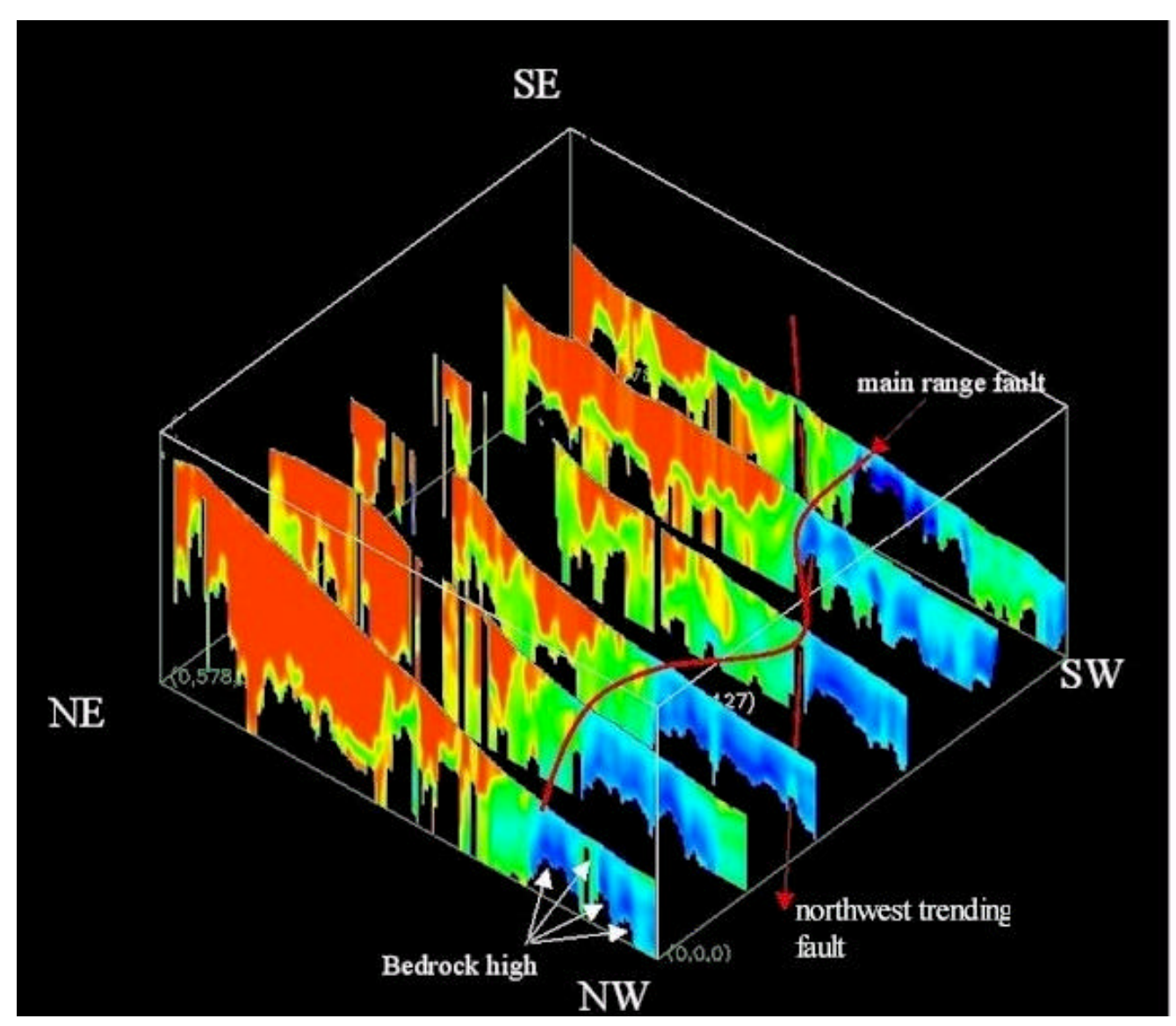

Extent of axes:

SW to SE: $12.6 \mathrm{~km}$

NW to SW: $8.5 \mathrm{~km}$

zaxis: $\quad 1.7 \mathrm{~km}$

Resistivity Key

(in $\log _{10} \mathrm{ohm}-\mathrm{m}$ )

Figure 34. Southeastward view of vertical slices through the three-dimensional representation of resistivity in the Cottonwood Canyon area, southern Arizona. Data-cube corner labels based on direction and shown in plate 2 .

\subsection{Summary of the Relation of Geophysical Data to the Geology and Mineral Resources of the Cottonwood Canyon Area}

Analysis of the magnetic anomaly map of the Cottonwood Canyon area (pl. 5) reveals no real surprises. The mineral deposits in the area are related to felsic intrusive bodies, some of which display a large magnetic anomaly. The mineralization itself tends to occur on magnetic gradients, but not everywhere. If the intrusive body related to mineralization is at depth in bedrock or represents a compositional change in a larger intrusive body also at depth in bedrock, it is difficult to analyze. The magnetic anomaly map does, however, contribute greatly to geologic understanding of the exposed bedrock and the basin.

In the basin fill, the magnetic anomaly map (pl. 5) may be particularly useful in a mineral-resource related sense. In the northwestern part of the study area (pl. 1; fig.1), the map appears to show where host rocks (unit PPn, pl. 2) concealed by basin fill are in contact with more magnetic rocks. This area could have a high potential for undiscovered polymetallic vein deposits (or other types of mineral deposits). 
CDTs are the model used in this study to interpret the TEM data. The CDTs do a good job of portraying conductivity in much of the terrain in the stud area (pl. 1; fig. 1). In some area, where highly resistive rocks occur at the surface, the S/N of the GEOTEM system is so low that no CDT solution can be calculated. In these areas, no information is displayed on the CDT - - likely a problem in the GEOTEM system but not in the CDT algorithm. If that is so, the only solution would be to use a more powerful transmitter.

The polymetallic vein deposits of the Cottonwood Canyon area (pl. 1;fig. 1) do have a geophysical signature in the CDTs. These deposits occur in bedrock that generally has a very low resistivity. These polymetallic vein deposits are associated with highconductivity regions that extend from deep in the bedrock to the surface. These regions can be quite narrow $(100 \mathrm{~m})$ or quite wide $(1 \mathrm{~km})$, but most are narrow. Every known mineral deposit or prospect in the Cottonwood Canyon area is associated with a high conductivity feature (fig. 35). These high conductivity features also occur without being associated with a known mineral deposit, as well as at depth where they may represent locations of undiscovered mineralization (see fig. 35). Even when the geophysical signature for a polymetallic vein deposits is visible at depth in bedrock (fig. 35), a mineral deposit does not necessarily occur there. Although the existence of the geophysical signal is not necessary and sufficient for the occurrence of polymetallic vein deposits, it is a strong indication of possible faulting and (or) mineralization in that area.

The airborne TEM data appear to be able to locate the basin-fill/bedrock contact beneath basin fill. The basin fill (dry and saturated) is generally more conductive than the bedrock; most of the energy in the TEM signal travels through this fill. The low conductivity of the bedrock ensures that no signal from the bedrock is received from beneath the basin fill in most places, and so the bedrock can be interpreted to be the bottom of the data on the CDTs in most areas of high conductivity basin fill.

Basin depths in the study area (pl. 1; fig. 1) based on the CDT data differ greatly from those estimated in a gravity-based study of basin depth (Gettings and Houser, 1997). Also, on the basis of the analysis in appendix 2, depths to bedrock in most of these regions of the CDTs are overstated by a factor of a least 2. Because CDTs based on airborne TEM data do not see into the bedrock below basin fill, the occurrence of mineralization in the bedrock concealed by basin fill cannot be ascertained.

Although three-dimensional analysis of the CDT data is useful for finding trends and features in the data that are difficult to see when looking at many individual CDT plots, it does not help distinguish the geophysical signature of polymetallic vein deposits. 

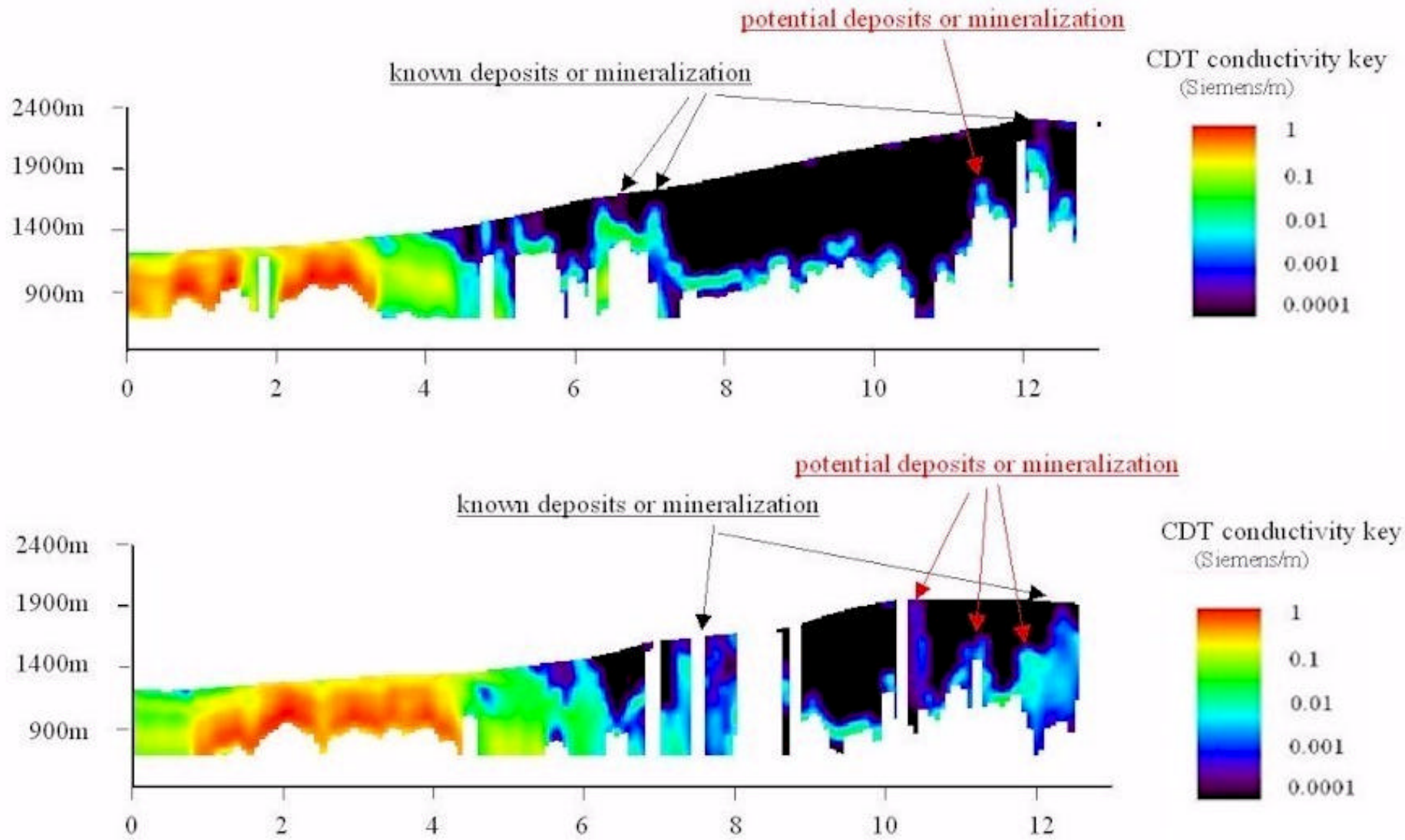

Figure 35. Examples of airborne TEM signatures of polymetallic vein deposits based on CDTs.

\section{Conclusions}

The objectives of this report were (1) to test whether known mineral deposits at or near the surface display any signal in the airborne TEM data; (2) to determine whether the TEM data can be used to locate bedrock concealed by basin fill; and (3) if the exposed mineral deposits display a signal in the TEM data, to determine whether any deposits are recognizable at depth in outcropping bedrock or in bedrock concealed beneath basin fill.

1. The polymetallic mineral deposits of the study area (pl. 1; fig. 1) have a geophysical signature in the CDTs that are calculated from TEM data. These deposits occur in bedrock that generally has a very low resistivity. The polymetallic vein deposits are associated with high conductivity regions that extend from deep in the bedrock to the surface. These regions can be quite narrow $(100 \mathrm{~m})$ or quite wide $(1 \mathrm{~km})$, but most are narrow. Every known mineral deposit or prospect in the Cottonwood Canyon area is associated with a high conductivity feature. These high conductivity features also occur without being associated with a known mineral deposit. 
2. The airborne TEM data appear to be able to locate the basin-fill/bedrock contact beneath basin fill. The basin fill (dry and saturated) is generally more conductive than the bedrock; most of the current travels through this fill. The low conductivity of the bedrock ensures that no signal from the bedrock is received from under the basin fill in most places, an so the bedrock can be interpreted to be the bottom of the data on the CDTs in most areas of high conductivity basin fill.

Basin depths in the study area (pl. 1; fig. 1) based on the CDT data differ greatly from those estimated in a gravity based study of basin depth (Gettings and Houser, 1997). Also, on the basis of the analysis in appendix 2, depths to bedrock in most of these regions of the CDTs are overstated by a factor of a least 2. Because CDTs based on airborne TEM data do not see into the bedrock below basin fill, the occurrence of mineralization in the bedrock concealed by basin fill cannot be ascertained.

3. The geophysical signature of polymetallic vein deposits is visible at depth in bedrock, but the existence of the geophysical signal is not necessary and sufficient for the occurrence of polymetallic vein deposits, although it is a strong indicator of possible mineralization in that area. Because CDTs based on airborne TEM data do not see into bedrock below basin fill, the occurrence of mineralization in the bedrock concealed by basin fill cannot be ascertained. 


\section{References Cited}

ADWR, accessed 1999, Arizona Department of Water Resources, Ground Water Site Inventory (GWSI) database, http://www.adwr.state.az.us/reference/gwsi.htm.

Baldyga, Christopher, 2000, Relationship of faults in basin sediments to the gravity and magnetic expression of their underlying fault systems, University of Arizona Master's Thesis, Department of Mining and Geological Engineering.

Bultman, M.W., 1999, Geometry, structure, and concealed lithology of the San Rafael basin, southeastern Arizona, U.S. Geological Survey Open-File Report 99-0399 (on-line).

Bultman, M.W. and Gettings, M. E, 1999, An interpretation of digital conductivity depth transform data from the 1997 Airborne Electromagnetic (AEM) survey, Fort Huachuca vicinity, Cochise County, Arizona, in Bultman, M.W., Gettings, M.E., and Wynn, Jeff, 1999, An interpretation of the 1997 Airborne Electromagnetic (AEM) survey, Fort Huachuca vicinity, Cochise County, Arizona, U.S. Geological Survey Open-File Report 99-0007-A (on-line) and B, (CD-ROM).

Bultman, M.W., Gettings, M.E., and Wynn, Jeff, 1999(a), A three-dimensional interpretation of an AEM survey in the upper San Pedro basin, Arizona, Symposium on the Application of Geophysics to Engineering and Environmental Problems 1999, Conference Proceedings, 10 p.

1999(b), An interpretation of the 1997 Airborne Electromagnetic (AEM) survey, Fort Huachuca vicinity, Cochise County, Arizona, U.S. Geological Survey OpenFile Reports 99-7-A (on-line) and 99-7-B (CD-ROM).

Drewes, Harold, 1971, Geologic map of the Mount Wrightson quadrangle, southeast of Tucson, Santa Cruz and Pima Counties, Arizona: U.S. Geological Survey Miscellaneous Geologic Investigations Map I-614, scale 1:48,000.

1980, Tectonic map of southeast Arizona: U.S. Geological Survey Miscellaneous Investigations Series Map I-1109, scale 1:125,000.

----- 1996, Geologic maps of the Coronado National Forest, southeast Arizona and southwest New Mexico: U.S. Geological Survey Bulletin 2083-B, p. 17-41.

Geoterrex-Dighem, 1997, Logistics and processing report of the airborne magnetic and GEOTEM electromagnetic survey over the Fort Huachuca Military Reservation, Cochise County, Arizona: Ottawa, Ontario, Canada, 14 p., 10 apps. 
Gettings, M.E., 1996, Aeromagnetic, radiometric, and gravity data for Coronado National Forest, in du Bray, E.A., ed., Mineral resource potential and geology of Coronado National Forest, Southeastern Arizona and Southwestern New Mexico, U.S. Geological Survey Bulletin 2083-D, p. 70-101.

------ 1999, An interpretation of the aeromagnetic data from the 1997 Airborne Electromagnetic (AEM) survey, Fort Huachuca vicinity, Cochise County, Arizona, in Bultman, M. W., Gettings, M. E., Wynn, Jeff; 1999, An interpretation of the 1997 Airborne Electromagnetic (AEM) survey, Fort Huachuca vicinity, Cochise County, Arizona, U.S. Geological Survey Open-File Report 99-0007-A (on-line) and B, (CD-ROM).

Gettings, M.E. and Bultman, M.W., 1993, Quantifying favorableness for occurrence of a mineral deposit type using fuzzy logic - an example from Arizona, U.S. Geological Survey Open-File Report 93-392, 23 p.

Gettings, P.E., and Gettings, M.E., 1996, Modeling of a magnetic and gravity anomaly profile from the Dragoon Mountains to Sierra Vista, southeastern Arizona: U.S. Geological Survey Open-File Report 96-288, 15 p.

Gettings, M.E., and Houser, B.B., 1995, Preliminary results of modeling the gravity anomaly field in the upper San Pedro basin, southeastern Arizona: U.S. Geological Survey Open-File Report 95-76, 9 p.

1997, Basin geology of the upper Santa Cruz Valley, Pima and Santa Cruz counties, southeastern Arizona, U.S. Geological Survey Open-File Report 97-676, $40 \mathrm{p}$.

------- 1999, Depth to bedrock of the Upper San Pedro Valley, Cochise County, Southeastern Arizona, U.S. Geological Survey Open-File Report.

Klein, D.P., and Bankey, V., 1992, Geophysical model of Creede, Comstock, Goldfield and related epithermal precious metal deposits, in Hoover, D.B., Heran, W.D., and Hill, P.L., 1992, The geophysical expression of selected mineral deposit models, U.S. Geological Survey Open-File report 92-557.

Kneale, Sean, Bultman, M.W., Chan, Tammy, Grisolano, Anna, and Hirschberg, Douglas, 1997, Coronado National Forest Geology: U.S. Geological Survey Administrative report to the U.S. Forest Service, Coronado National Forest.

Macnae, J.C., Smith, R., Polzer, B.D., Lamontagne, Y., and Klinkert, P.S., 1991, Conductivity-depth imaging of airbourne electromagnetic step-response data: Geophysics, v. 56. no. 1, p. 102-114.

Pool, D.R., 1999, Geophysical investigations near Fort Huachuca, Cochise County, Arizona: manuscript, $47 \mathrm{p}$. 
Wynn, Jeff, 1999, A description, comparison to other data, and interpretation of the electromagnetic data from the 1997 Airborne Electromagnetic (AEM) survey, Fort Huachuca vicinity, Cochise County, Arizona, in Bultman, M.W., Gettings, M.E., Wynn, Jeff; 1999, An interpretation of the 1997 Airborne Electromagnetic (AEM) survey, Fort Huachuca vicinity, Cochise County, Arizona, U.S. Geological Survey Open-File Report 99-7-A (on-line) and 99-7-B. 


\section{Appendix 1.}

Data from the Cottonwood Canyon airborne time-domain electromagnetic survey of the Cottonwood Canyon area, southern Arizona

$\underline{\text { Click here to view data files }}$ 


\section{Appendix 2. \\ Comparison of CDT-Based Depth Estimates with Gravity Based Depth Estimates, Cottonwood Canyon Area, Arizona}

A recent study by Baldyga (2001) analyzed the relation of faults in basin fill to the magnetic and gravity expression of their underlying (bedrock) fault systems. Baldyga acquired closely spaced gravity and magnetic data along two profiles in the Cottonwood Canyon, Ariz. area, named the northern and southern profiles. From these data, forward models of subsurface geology were calculated and displayed on two cross sections. These models included the depth to bedrock beneath the basin fill. The spatial density of the data contributes to the accuracy of the models.

The profiles and their interpreted cross sections in Baldyga's (2001) study lie within the study area of this report. Although the flightlines (and corresponding CDTs) are eastwest, Baldyga's profiles have a slight northeastward trend (see Baldyga, 2000, p. 56) and correspond to the eastern part of two of the flightlines. In these areas, Baldyga's profiles are used to test the estimates of depth to bedrock in this study that are based on TEM data.

The basin fill includes both the upper basin fill and the more consolidated underlying Nogales formation. In section 2.3.b, above, the depth to bedrock in the basin fill is estimated to be the depth to the bottom of the CDT data. The conductivities of dry and saturated basin fill are high relative to those of bedrock. The electromagnetic energy is dissipated in the highly conductive basin fill, and no signal is acquired from the resistive bedrock below the fill. The bottom of the CDT data then defines the geometry of the basin-fill/bedrock contact.

The cross section from Baldyga's (2001) northern profile is shown in fig. A2-1. A red line has been added to indicate the basin-fill/bedrock contact. Figure A2-2 shows Baldyga's northern profile and the CDT nearest to Baldyga's northern profile, CDT 8. Both the profile and the CDT are geographically registered to a geologic map which also shows the position of the flight line that acquired CDT 8 and of Baldyga's northern profile. To be horizontally scaled the same as CDT 8, Baldyga's cross section had to be compressed in an east-west sense; as a result, any text on it was made unreadable. Also, the patterns used to indicate the different rock types tended to blur together. The red line used to indicate the basin-fill/bedrock contact (that was placed on fig. A2-1) remains. 


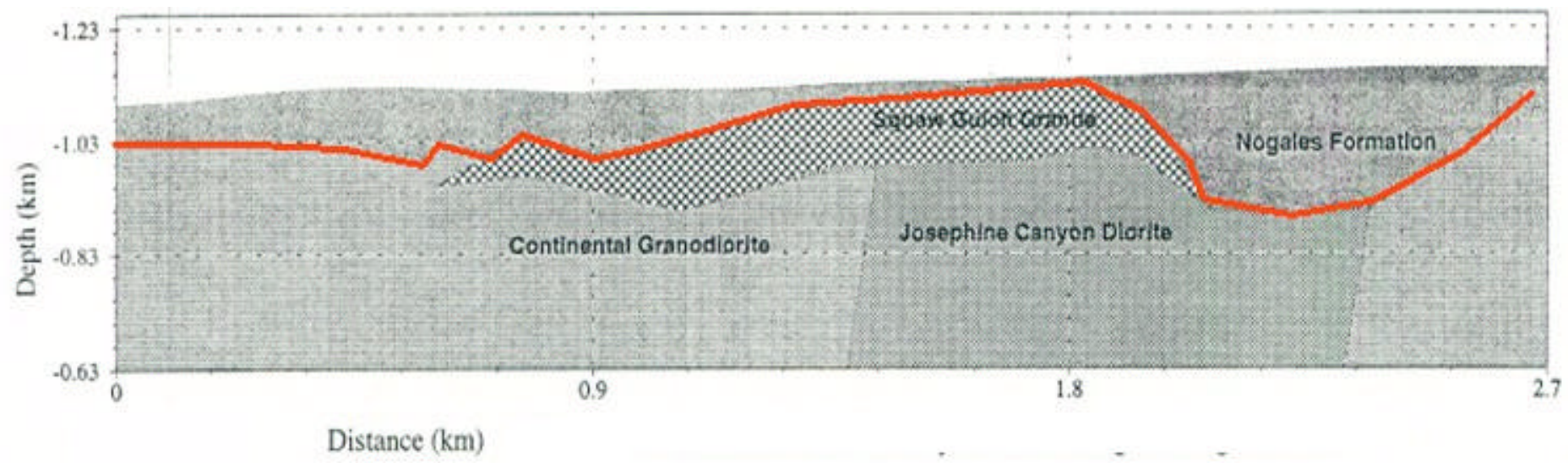

Figure A2-1. Cross section from Baldyga's (2001) northern profile

(Red line denotes basin-fill/bedrock contact.)

Gravity-

based

depth

estimate

(from

Baldyga

2001)

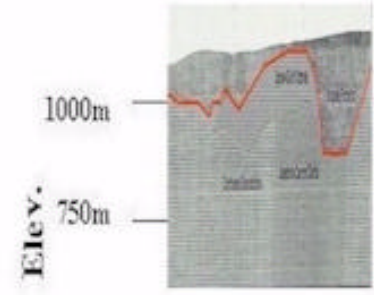

CDT

White areas

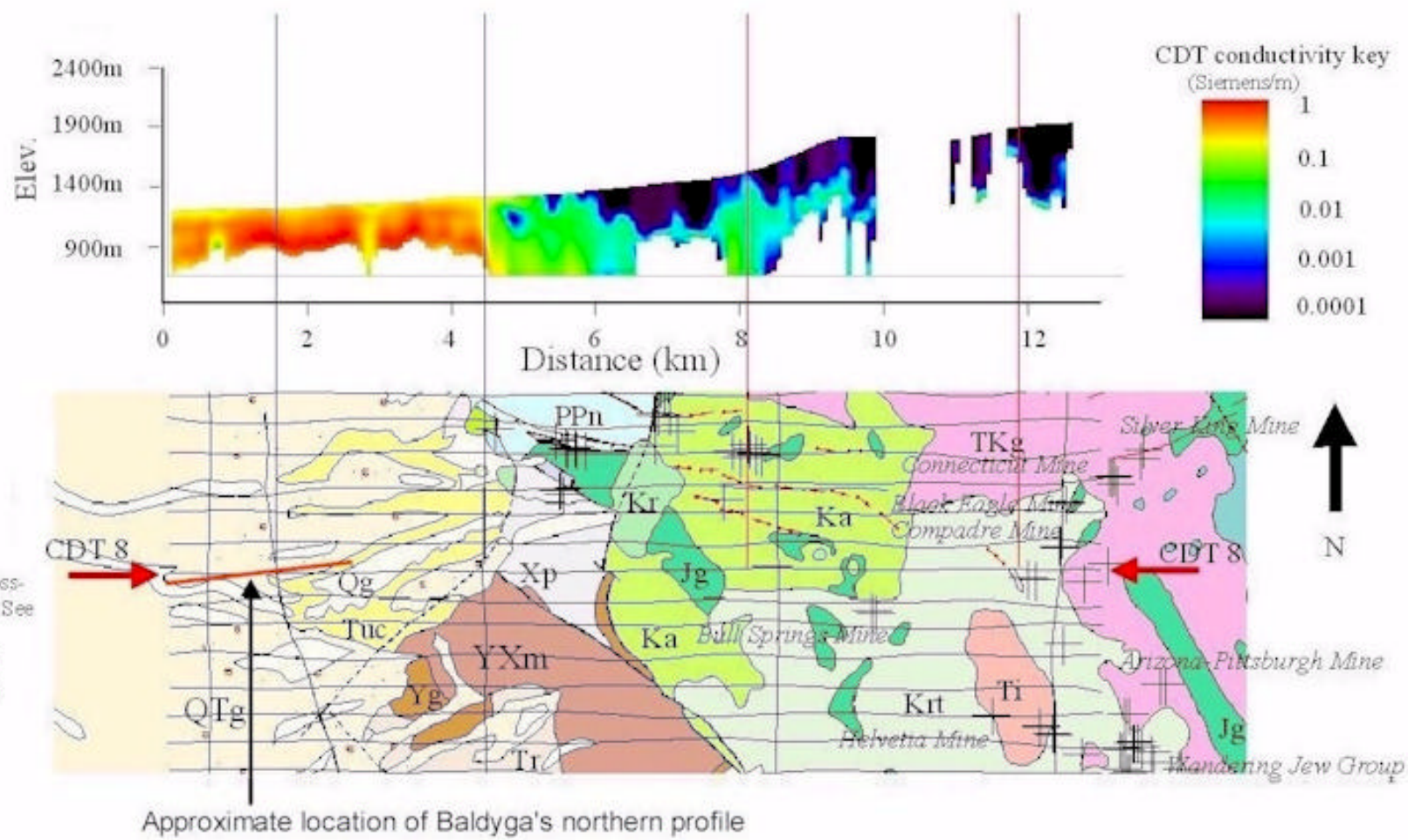

Geologic map with flightines

profile and crosssection abore See plate 2 for description of geologicunits

Figure A2-2. CDT 8 georeferenced to Baldyga's (2001) northern profile and geologic map. Click here to view at a higher resolution. 
A comparison of the basin-fill/bedrock contact between Baldyga's (2001) cross section and CDT 8 in figure A2-2 shows several differences. First, the depth to bedrock is overestimated on the CDTs. Depth to bedrock ranges from less than $50 \mathrm{~m}$ to about $200 \mathrm{~m}$ in Baldyga's cross section, whereas depth to bedrock ranges from about 300 to almost $500 \mathrm{~m}$ in CDT 8.

Second, although offsets in the geometry of the basin-fill/bedrock contact appear similar in the cross section and CDT 8, they are muted on CDT 8 and lie at exaggerated depths relative to the cross section (for example, line A2-2a, fig. A2-2). In this area a fault creates a large offset on the gravity-based model. The offset of the basin-fill/bedrock contact is about $200 \mathrm{~m}$, and the up-thrown bedrock block is about $50 \mathrm{~m}$ deep. The same fault appears in CDT 8, and the bedrock is offset in the same direction as in the cross section, but the offset in the CDT is less than $100 \mathrm{~m}$ and the upthrown bedrock block is about $400 \mathrm{~m}$ deep.

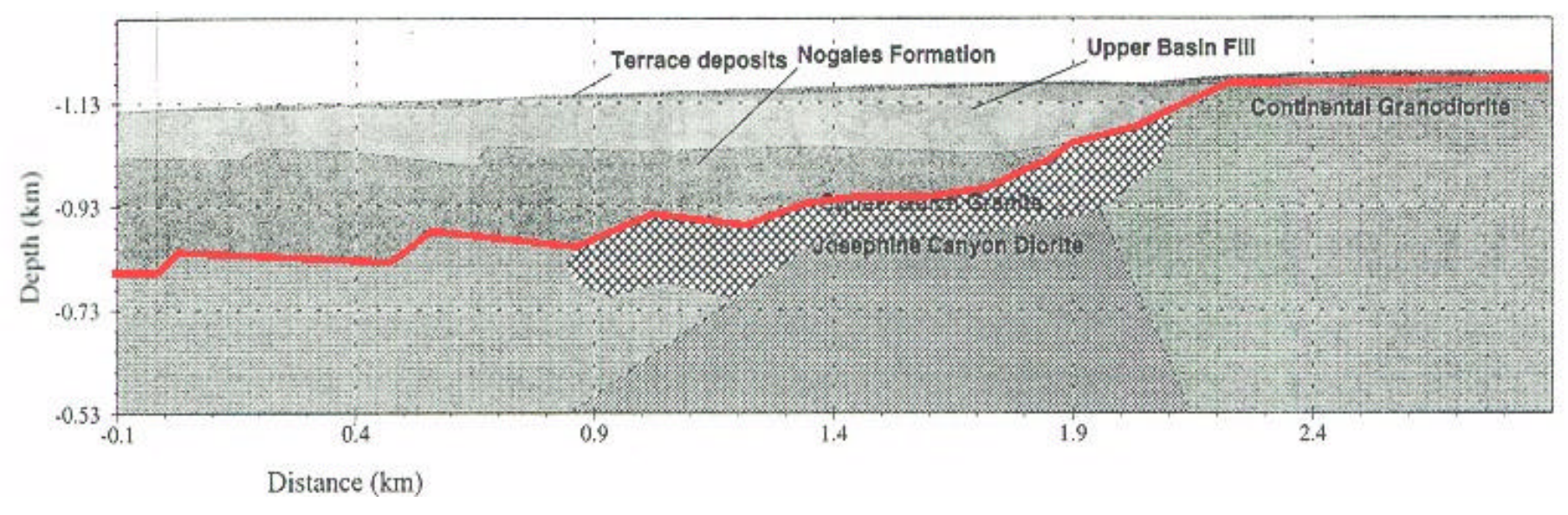

Figure A2-3. Cross section from Baldyga's (2001) southern profile.

Fig. A2-3 shows the cross section from Baldyga's (2001) southern profile, which lies about $1 \mathrm{~km}$ south of the northern profile. Baldyga's southern profile lies closest to the western part of CDT 11. Fig. A2-4 shows Baldyga's southern profile, CDT 11 and a geologic map, all georeferenced to each other. 


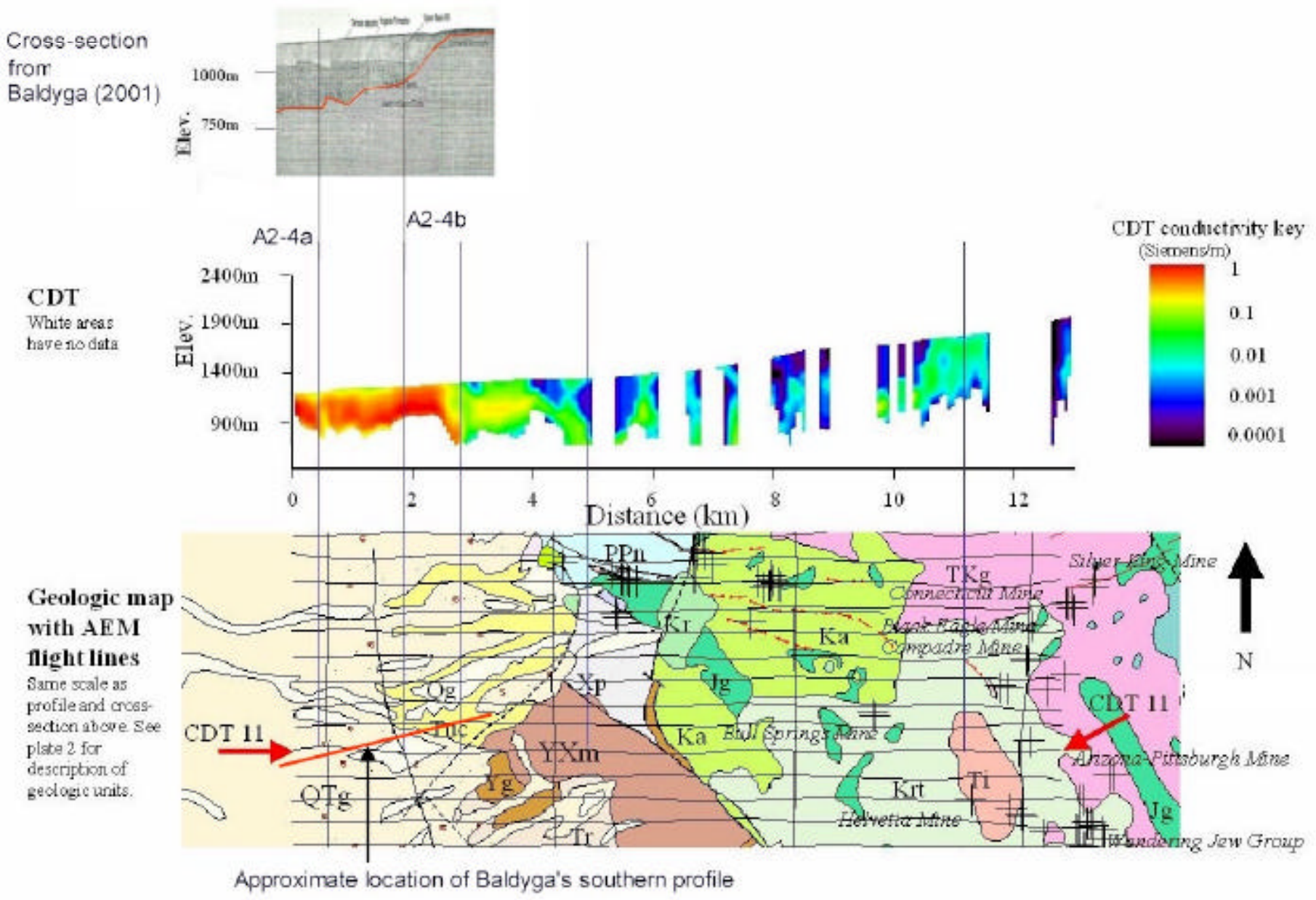

Figure A2-4. CDT 11 georeferenced to Baldyga's (2001) southern profile and geologic map Click here to view at a higher resolution.

Two lines (A2-4a and A2-4b) in figure A2-4 are drawn between Baldyga's (2001) cross section and the CDT. Just east of line A2-4a in Baldyga's cross section is an upthrown bedrock block at about $250 \mathrm{~m}$ depth; the same feature is visible in CDT 11 at about 400 $m$ depth. As in CDT 8, similar features are visible in the cross section and in the CDT, but the CDT seems to overestimate depth, and the amount of vertical displacement of this bedrock block seems to be understated in the CDT.

At line A2-4b in figure A2-4, a mapped fault is crossed, and the basin rapidly shallows eastward on the basis of the information in the cross section. In the CDT, the basinfill/bedrock contact tends to remain at a constant depth. The interpretation of the CDT indicates that exposed bedrock (which may be covered with very thin alluvium, a few meters thick or less) is reached when a major decrease in conductivity occurs at the surface, at approximately the same point where the basin-fill/bedrock contact reaches its shallowest in Baldyga's (2001) cross section. Thus, as the basin shallows, the CDT 
drastically overestimates depth to bedrock but still accurately indicates the location of the mapped basin-fill/bedrock contact on the surface.

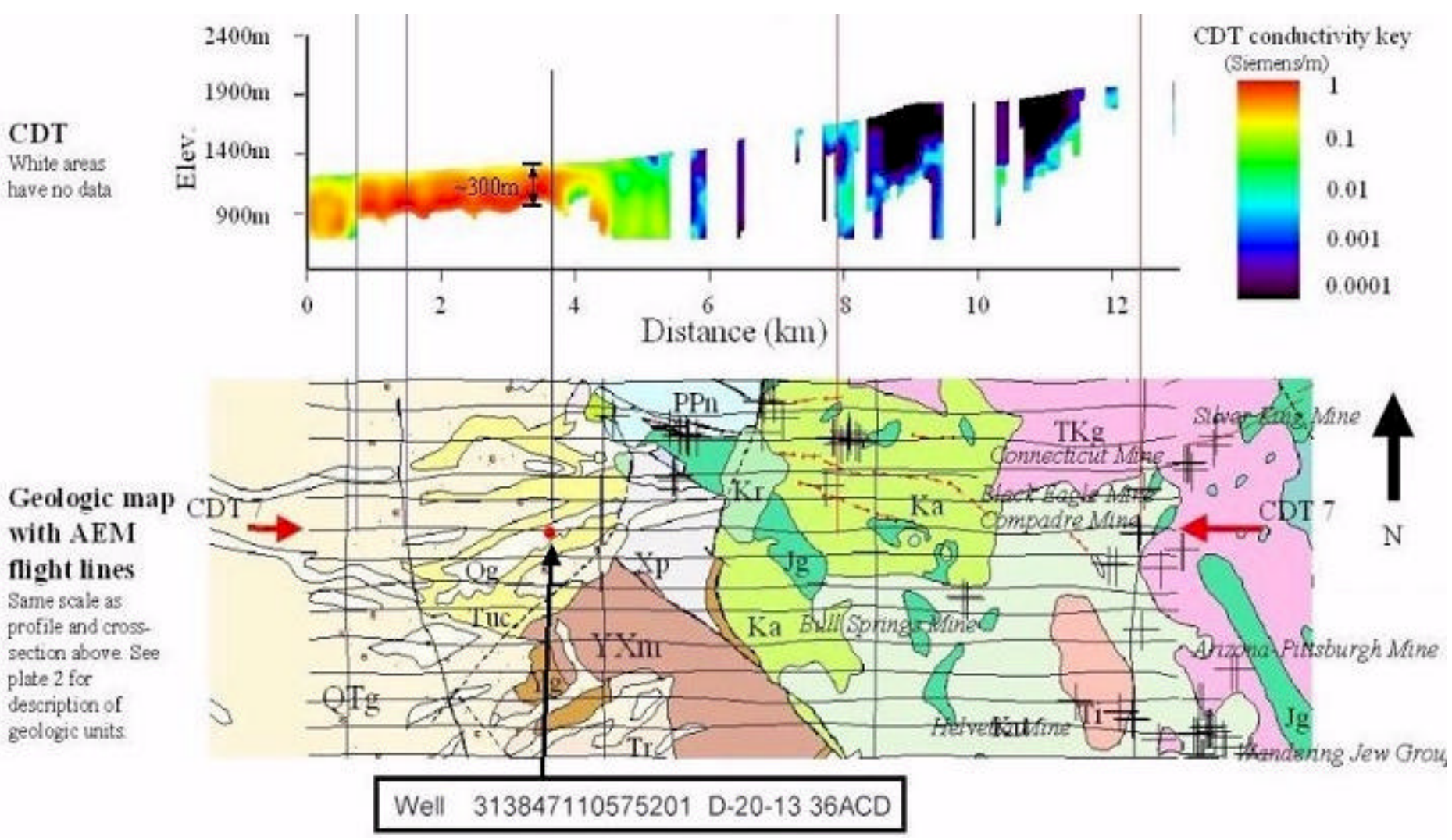

\section{Figure A2-5. Location of water well 'D-20-13 36ACD" and CDT 7}

\section{Click here to view at a higher resolution.}

Figure A2-5 shows the location of a water well on the geologic map. CDT 7, which passes almost directly over this water well, is shown above the geologic map and georeferenced to the geologic map. The water well is $90 \mathrm{~m}$ deep and lies entirely in basin fill. The estimated depth to bedrock at the well is $160 \mathrm{~m}$ (Gettings and Houser, 1999). The estimated depth of the basin-fill/bedrock contact at this location is about $300 \mathrm{~m}$, on the basis of CDT 7. The well is located near the surface outcrop of the basin-fill/bedrock contact, where CDT-based depth estimates can poor, as demonstrated above. 


\section{Summary}

Large discrepancies exist between gravity based forward models of the depth of overburden and CDT-based estimates in the Cottonwood Canyon area. Experience in southern Arizona with numerous gravity-based models indicates that they are fairly accurate. On this basis, depth estimates of basin fill based on CDTs derived from TEM data may be overestimated by a factor of at least 2. Also, vertical displacement of the basin-fill/bedrock contact concealed by basin fill may be muted in the CDTs, although the CDTs do map the outcrop of this contact quite well.

\section{References Cited}

Baldyga, Christopher, 2001, Relationship of faults in basin sediments to the gravity and magnetic expression of their underlying fault systems: U.S. Geological Survey Open-File Report 01-502.

Gettings, M.E. and Houser, B.B., 1997, Basin geology of the upper Santa Cruz Valley, Pima and Santa Cruz counties, southeastern Arizona: U.S. Geological Survey Open-File Report 97-676, 40 p. 